\title{
ESTUDOS GEOQUÍMICOS DE ITABIRITOS DA SERRA DO SAPO, ESPINHAÇO MERIDIONAL, MINAS GERAIS
}

\author{
Amanda A. Pires e Souza ${ }^{1}$, Rosaline Cristina Figueiredo e Silva ${ }^{2}$, Carlos Alberto Rosière ${ }^{2}$, \\ Geraldo Sarquis Dias ${ }^{3}$, Fernando Prudêncio Morais ${ }^{3}$ \\ 1 - Programa de Pós-Graduação em Geologia da UFMG, Instituto de Geociências, Universidade Federal de Minas Gerais - UFMG, Avenida Antônio \\ Carlos 6627, CEP 31270-901, Belo Horizonte, MG, BR. amanda.de.aps@gmail.com \\ 2 - Centro de Pesquisa Professor Manoel Teixeira da Costa, Instituto de Geociências, Universidade Federal de Minas Gerais - UFMG, Avenida Antônio \\ Carlos 6627, CEP 31270-901, Belo Horizonte, MG, BR. rosalinecris@yahoo.com.br; crosiere@gmail.com \\ 3 - Anglo American, Projeto Minas-Rio, CEP 35860-000, Conceição do Mato Dentro, MG, BR.geraldo.dias@angloamerican.com; \\ fernando.morais@angloamerican.com
}

Recebido em 15 de novembro de 2014; aceito em 19 de março de 2015

Resumo: A Serra do Sapo localiza-se na porção leste da Serra do Espinhaço Meridional, nas proximidades do município de Conceição do Mato Dentro, Minas Gerais, Brasil. Nessa região, formações ferríferas bandadas são metamorfizadas e intensamente cisalhadas. De acordo com o grau de intemperismo e compacidade, minérios de ferro com teores entre 31 e $39 \%$ Fe são classificados em itabirito, itabirito semifriável e itabirito friável. Cristais de hematita são classificados de acordo com suas características texturais e morfológicas em microlamelar, anédrica, lamelar e martita. Análises químicas de rocha total mostram que os três tipos de itabirito são semelhantes com conteúdo de $\mathrm{CaO}(\leq 0,14 \mathrm{wt} \%), \mathrm{MgO}(\leq 0,04 \mathrm{wt} \%), \mathrm{MnO}(\leq 0,21 \mathrm{wt} \%), \mathrm{Al}_{2} \mathrm{O}_{3}(\leq 0,94 w t \%), \mathrm{K}_{2} \mathrm{O}(\leq 0,27 \mathrm{wt} \%), \mathrm{TiO}_{2}(\leq 0,05 \mathrm{wt} \%)$ e $\mathrm{P}_{2} \mathrm{O}_{5}(\leq$ 0,11 wt\%), entretanto com as maiores concentrações de $\mathrm{Al}_{2} \mathrm{O}_{3}, \mathrm{MgO}$ e $\mathrm{K}_{2} \mathrm{O}$ presentes nos itabiritos semifriável e friável, e as de CaO e $\mathrm{P}_{2} \mathrm{O}_{5}$ no itabirito. $\mathrm{O}$ teor em $\mathrm{U}$ autigênico, e as relações $\mathrm{V} / \mathrm{Cr}$ e Ni/Co do itabirito apontam para um ambiente de sedimentação oxidante para a formação ferrífera bandada. Razões $(\mathrm{Eu} / \mathrm{Sm})_{S N},(\mathrm{La} / \mathrm{Sm})_{C_{N}},(\mathrm{Sm} / \mathrm{Yb})_{S_{N}},\left(E u / E u^{*}\right)_{S N}$, e $(\mathrm{Sm} / \mathrm{Yb})_{C_{N}}$ indicam que a formação ferrífera bandada mais fresca, representada pelo itabirito, está livre de contaminação clástica. Já as razões de $\mathrm{Sm} / \mathrm{Yb}$ vs. Eu/Sm e de Eu/Eu* ${ }_{(\mathrm{CN})} v s$. (Sm/Yb) ${ }_{(\mathrm{CN})}$ indicam contribuição insignificante por fluidos hidrotermais de alta temperatura.

Palavras Chave: Serra do Sapo; Serra do Espinhaço Meridional; Formação ferrífera bandada; Geoquímica.

Abstract: GEOCHEMICAL STUDIES OF ITABIRITES FROM SERRA DO SAPO, SOUTHERN ESPINHAÇO, MINAS GERAIS. The Serra do Sapo is located on east side of the southern portion of Serra do Espinhaço, near the city of Conceição do Mato Dentro, Minas Gerais, Brazil. In the area banded iron formation are metamorphosed and slightly sheared. Supergene low to medium- grade iron ore (31 to $39 \%$ Fe) are classified in itabirite, semi-friable itabirite and friable or soft itabirite, according to the degree of weathering and compactness. Hematite crystals were classified after their textural and morphological characteristics as: microplaty, anhedral, platy, and martite (pseudomorphic after magnetite). Geochemical analysis show that the three types of itabirites are similar regarding the content of $\mathrm{CaO}(\leq 0,14 \mathrm{wt} \%), \mathrm{MgO}(\leq$ $0,04 w t \%), \mathrm{MnO}(\leq 0,21 w t \%), \mathrm{Al}_{2} \mathrm{O}_{3}(\leq 0,94 w t \%), \mathrm{K}_{2} \mathrm{O}(\leq 0,27 w t \%), \mathrm{TiO}_{2}(\leq 0,05 w t \%)$ e $\mathrm{P}_{2} \mathrm{O}_{5}(\leq 0,11$ wt $\%)$, with higher grades of $\mathrm{Al} \mathrm{O}_{3}, \mathrm{MgO}$ and $\mathrm{K}_{2} \mathrm{O}$ present in semi-friable and friable itabirites and, of $\mathrm{CaO}$ and $\mathrm{P}_{2} \mathrm{O}_{5}$ in itabirite. The autigenic $\mathrm{U}, \mathrm{V} / \mathrm{Cr}$ and Ni/Co indexes point to an oxic environment of sedimentation. Ratios of $(\mathrm{Eu} / \mathrm{Sm})_{\mathrm{SN}},(\mathrm{La} / \mathrm{Sm})_{\mathrm{CN}_{N}},(\mathrm{Sm} / \mathrm{Yb})_{\mathrm{SN}},\left(\mathrm{Eu} / \mathrm{Eu}^{*}\right)_{\mathrm{SN}}$, and $(\mathrm{Sm} / \mathrm{Yb})_{\mathrm{CN}}$ indicate that the banded iron formation represented by the itabirite is free of clastic contamination and the ratios of Sm/Yb vs. Eu/Sm and of Eu/Eu* ${ }_{(\mathrm{CN})} v s$. (Sm/Yb) ${ }_{(\mathrm{CN})}$ indicate insignificant contribution of high temperature hydrothermal fluids.

Keywords: Serra do Sapo; Serra do Espinhaço Meridional; Banded iron formation; Geochemistry.

\section{INTRODUÇÃO}

A Serra do Sapo está localizada na borda leste da Serra do Espinhaço (Eschwege, 1822 in AlmeidaAbreu \& Renger, 2002). A Serra do Espinhaço situase a aproximadamente $150 \mathrm{~km}$ ao norte do Quadrilátero Ferrífero, com mais de $1200 \mathrm{~km}$, trend $\mathrm{N}-\mathrm{S}$, atravessando os estados da Bahia e de Minas Gerais, onde é dividida em dois domínios, Setentrional e Meridional, próxima ao paralelo 1700's, (Knauer, 2007).

A borda leste da Serra do Espinhaço Meridional compreende as principais ocorrências de formações ferríferas conhecidas da Serra do Espinhaço (Knauer, 2007), abrangendo os grupos Itapanhoacanga (Rolim \& Rosière, 2011) e Serra da Serpentina (Dossin, 1985, Almeida-Abreu et al., 1989, Rolim \& Rosière, 2011). O Grupo Itapanhoacanga, segundo Rolim (2014), é predominantemente composto por quartzitos apresentando formações ferríferas nas porções superiores. O Grupo Serra da Serpentina
(Grossi Sad et al., 1997; Knauer \& Grossi-Sad, 1997; Almeida Abreu \& Renger, 2002) aflora na serra homônima e na Serra do Sapo, e consiste em quartzo xistos, quartzitos, filitos e formação ferrífera bandada (FFB).

Minério de ferro de baixo teor compreende itabirito com diferentes graus de alteração intempérica, classificados como itabirito (IT), itabirito semifriável (ISF) e itabirito friável (IF), e tem sido explorado pela Anglo American ao longo da Serra do Sapo. As estimativas de recursos de minério de ferro estão em torno de 5,3 bilhões de toneladas, com potencial para atingirem 8 bilhões de toneladas. 0 início da produção aconteceu no final de 2014.

Este trabalho apresenta os estudos petrográficos e geoquímicos dos diferentes tipos de itabirito (IT, ISF e IF), com o propósito de identificar e caracterizar os minerais minérios e de ganga, identificar o ambiente deposicional da FFB, assim como verificar se houve contaminação clástica ou 
alguma contribuição hidrotermal na FFB. Pretendese ainda identificar possíveis contaminações, como por exemplo $\mathrm{P}, \mathrm{Mn}$, e caracterizar os tipos de itabirito, no intuito de auxiliar trabalhos futuros de classificação industrial/geometalúrgica.

\section{CONTEXTO GEOLÓGICO}

A Serra do Sapo está localizada a aproximadamente $15 \mathrm{~km}$ a nordeste do Município de Conceição do Mato Dentro, região sudeste do Estado de Minas Gerais. A área faz parte da Serra do Espinhaço Meridional - SdEM - faixa orogênica que representa a zona externa da Faixa Araçuaí, a qual bordeja a sudeste o Cráton do São Francisco (Uhlein 1991, Brito Neves \& Cordani, 1991, Trompette et al., 1992, Schobbenhaus, 1993, 1996, Alkmim et al., 1993 in Martins-Neto, 1998), estendendo-se por cerca de $300 \mathrm{~km}$ em direção N-S, desde o Quadrilátero Ferrífero até a região de Olhos d'Água. A estratigrafia da SdEM foi inicialmente descrita por Pflug (1968) e Schöll \& Fogaça (1979), com modificações propostas por Fogaça et al. (1984), Dossin et al. (1984) e Almeida Abreu (1993). Posteriormente, Almeida-Abreu \& Renger (2002) e Knauer (2007) também sugeriram modificações.

A Serra do Espinhaço Meridional engloba as principais ocorrências de FFBs conhecidas na Serra do Espinhaço. A forte tectônica tangencial sob a qual a área foi submetida dificulta uma boa caracterização das relações de contato e do posicionamento estratigráfico relativo das sequências (Knauer, 1990). A área apresenta três depósitos principais de minério de ferro, os quais pertencem ao Grupo Serra da Serpentina, e estão localizados nas serras do Sapo e da Serpentina, e no Morro do Pilar (Rolim \& Rosière, 2011) (Fig. 1).

O depósito da Serra do Sapo, ao norte de Conceição do Mato Dentro, tem $15 \mathrm{~km}$ de extensão, e a camada de FFB tem em média $120 \mathrm{~m}$ de espessura, podendo atingir $350 \mathrm{~m}$ no seu extremo norte (Rolim \& Rosière, 2011).

O Grupo Serra da Serpentina, segundo Rolim \& Rosière (2011), é composto por uma unidade basal pelítica constituída por quartzo-mica xistos associados a quartzitos finos e xistos negros ricos em manganês, folhelhos negros e xistos sericíticos. Xistos de cor negra e cinza do topo da unidade fazem contato direto com a FFB. Lentes de metadolomito e mármore dolomítico ocorrem próximas à Vila de Itapanhoacanga ao norte de Conceição do Mato Dentro, contendo veios de quartzo e/ou de calcita que dão aparência brechada à rocha. Quartzito metaconglomerático sericítico, clasto-suportado e com clastos da FFB, cobre a unidade da FFB. Clastos de quartzitos, FFB, mica xistos, e filitos também são encontrados na matriz rica em quartzo. Uma unidade superior de FFB com características litológicas e mineralógicas idênticas à da FFB anterior, ocorre no topo com 10 a $30 \mathrm{~m}$ de espessura.

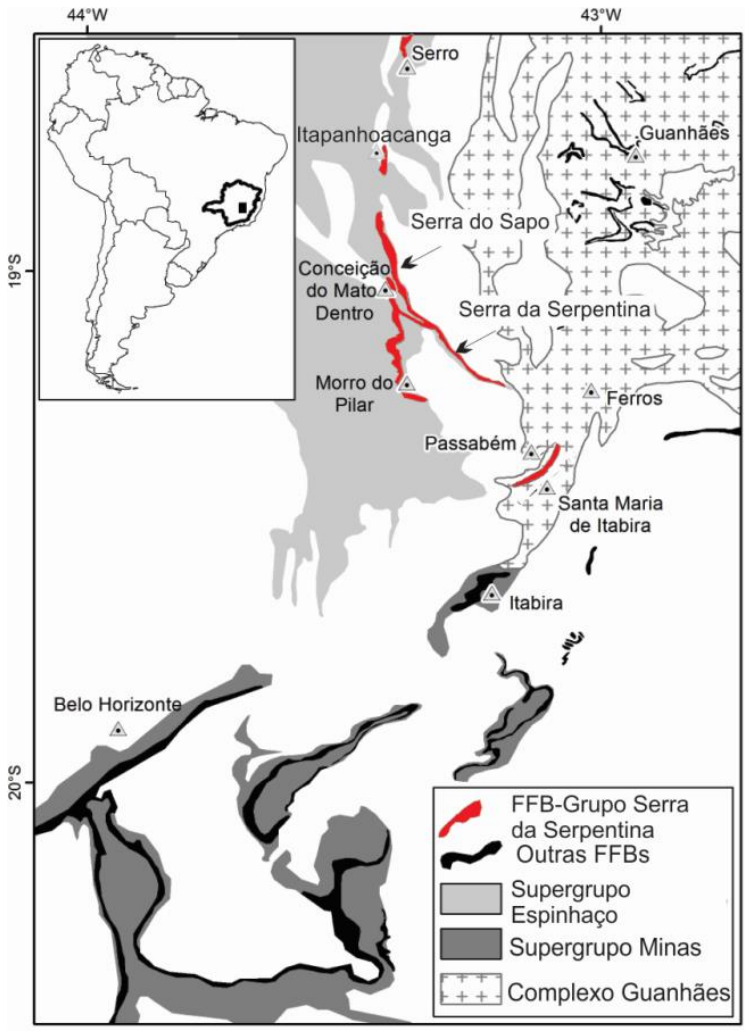

Figura 1. Mapa geológico regional mostrando a localização das FFBs do Grupo Serra da Serpentina, e a distribuição das outras sequências de FFBs no sudeste do Brasil (modificado de Rolim \& Rosière 2011).

Idades $\mathrm{U}-\mathrm{Pb}$ em zircões detríticos e magmáticos apresentadas por Chemale Jr. et al. (2012) permitiram uma nova visão sobre a história evolutiva da denominada Bacia Espinhaço. Idades U$\mathrm{Pb}$ obtidas em zircões da seção basal da Fm. SopaBrumadinho com pico em 1192Ma, e de intrusão de diques máficos da Suíte Pedro Lessa (Machado et al., 1989) que cortam as unidades do Supergrupo Espinhaço, com idade próxima a 900Ma, estabeleceram uma idade Esteniana-Toniana para a porção superior da bacia (Chemale Jr. et al. 2012). Rolim \& Rosière (2011) obtiveram uma idade mínima preliminar de $2050 \mathrm{Ma}$ (U-Pb SHIRIMP) a partir de zircões detríticos de metaconglomerados de uma camada localizada logo acima das FFBs do Grupo Serra da Serpentina, o que sugere que este é mais antigo que o Supergrupo Espinhaço, e mais novo que a Formação Cauê do Supergrupo Minas, a qual tem idade de sedimentação entre 2580Ma (base da Formação Moeda) e 2050Ma (topo do Grupo Sabará) segundo Renger et al. (1994) e 
portanto não pode ser correlacionado a nenhuma dessas sequências.

\section{MATERIAIS \& MÉTODOS}

\subsection{Amostragem e Petrografia}

Foram selecionados e descritos 7 de furos de sondagem representativos do depósito, 65 amostras foram coletadas nos furos e 37 lâminas delgadas polidas foram confeccionadas para realização de estudos mineralógicos e petrográficos os quais foram realizados no Laboratório de Metalogenia do CPMTC.

\subsection{Geoquímica}

Estudos geoquímicos de rocha total foram realizados no Laboratório AcmeLabs - ACME Analytical Laboratories Ltd. (Canadá). Foram analisadas 15 amostras de testemunho de sondagem, incluindo itabiritos e hematita em veios de quartzo, levando em conta a maior variabilidade dos tipos de óxidos de ferro.

Os métodos utilizados para as análises quantitativas foram ICP-ES (Inductively Coupled Plasma Emission Spectrometric) e ICP-MS (Inductively Coupled Plasma Mass Spectroscopy).0 primeiro foi realizado com fusão da amostra por metaborato de lítio e digestão com $\mathrm{HNO}_{3}$, para os óxidos maiores e elementos menores. O segundo com fusão da amostra por metaborato e tetraborato de lítio, e digestão com água régia (apenas metaisbase), para elementos traços e terras raras.

\section{PETROGRAFIA}

No depósito da Serra do Sapo, as FFBs são metamorfizadas e intensamente cisalhadas com transposição e obliteração das estruturas primárias sendo observadas na maioria dos afloramentos. Minérios de ferro de baixo teor (31 a 39\% Fe) foram classificados em itabirito-IT, itabirito semifriável-ISF e itabirito friável-IF (Fig. 2). Esta classificação foi feita com base nas descrições petrográficas macroscópicas, e de acordo com o grau de intemperismo e compacidade apresentado pelas amostras (Figs. 3-A, 3-B e 3-C; Tab. 1).

O termo itabirito é usado para denominar a FFB fracamente ou não intemperizada, sendo constituída essencialmente por óxidos de ferro e quartzo. A rocha apresenta intervalos magnéticos e é cortada por veios de quartzo com hematita especularítica, de espessuras centimétricas a métricas. Esses veios, de provável origem hidrotermal, também são aqui descritos.

A alteração intempérica do IT produz sua desagregação gerando os tipos denominados ISF e IF (Fig. 3-B e 3-C). O itabirito friável corresponde ao produto final mais avançado de intemperismo que ocorre em geral nas partes superiores das zonas do saprólito (Fig. 4).

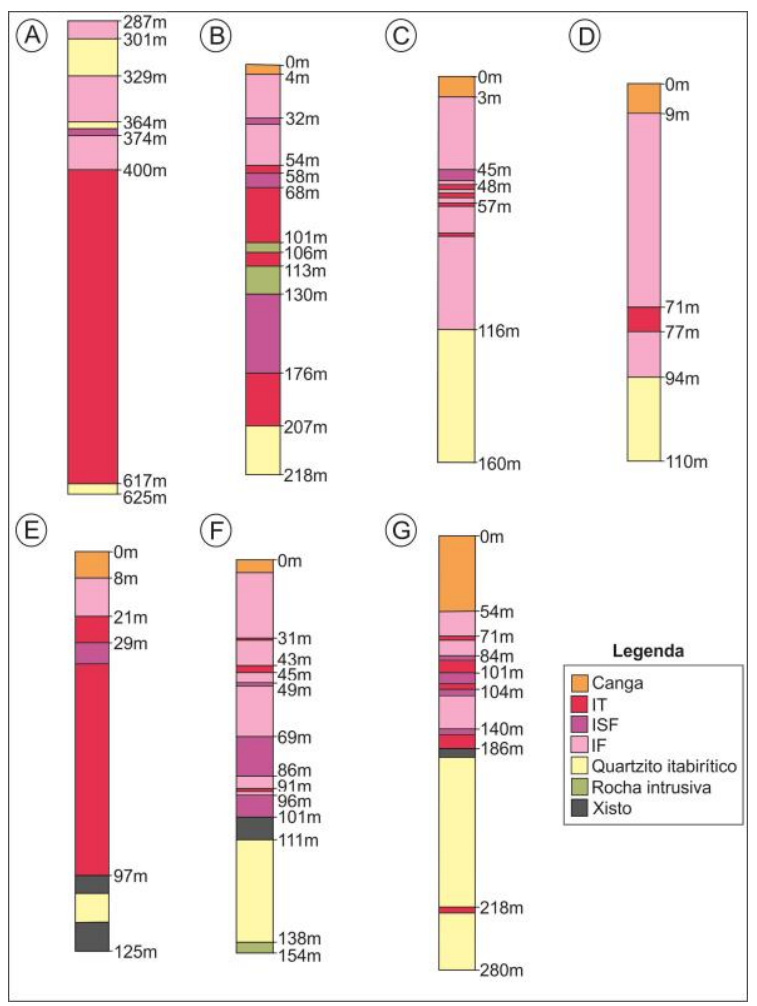

Figura 2. Desenhos esquemáticos representativos dos furos de sondagem descritos: (A): FD115; (B): FD144; (C): FD 152; (D): FD195; (E): FD201; (F): FD 408; (G): FD521.
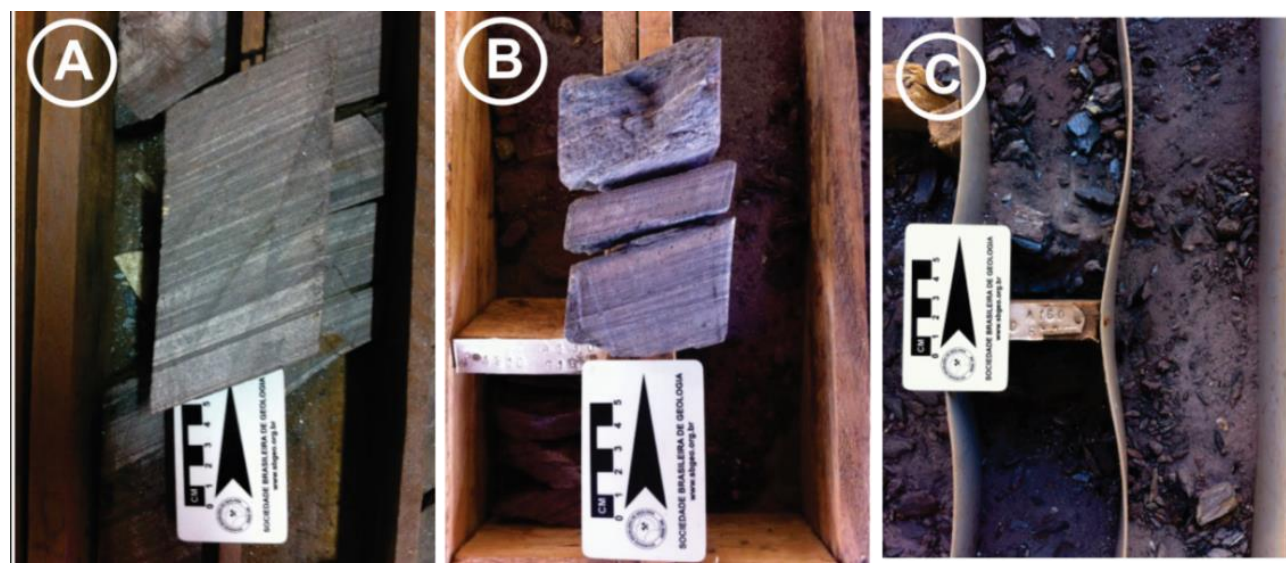

Figura 3. (A): Amostra de itabirito; (B): Amostra de itabirito semifriável; (C): Porção do itabirito friável com presença de fragmentos. 
Tabela 1. Tabela de descrição das amostras nas quais foram realizadas análises químicas de rocha total. Siglas: MpHem - hematita microlamelar; AHem - hematita anédrica; PHem - hematita lamelar; Mt - martita; Kmg-kenomagnetita; Gt - Goethita; Qtz-quartzo; Mbr-mica branca; Chl-clorita; Gbs - Gibsita.

\begin{tabular}{|c|c|c|c|c|c|c|c|c|c|c|c|}
\hline $\begin{array}{l}\text { Amostra } \\
\text { FD: }\end{array}$ & $\begin{array}{c}\text { Descrição da } \\
\text { amostra/Mineralogia }\end{array}$ & $\mathrm{MpH}$ & AHem & Mt & Kmg & PHem & Gt & Qtz & Mbr & Gbs & Chl \\
\hline 201-1 & IT & $x x$ & $x x$ & & & & & $\mathrm{xx}$ & & & \\
\hline 201-2 & ISF & $x x$ & & & & & & $\mathrm{xx}$ & $x$ & & \\
\hline 201-3 & IT (contato com veio) & $x x$ & $x x$ & & & & & $x x$ & $x$ & & \\
\hline 201-4 & IT & $x x$ & $x x$ & $x$ & & & & $x x$ & & & \\
\hline 201-7 & IT & $x x$ & $\mathrm{x}$ & & & & & $x x$ & $x$ & & \\
\hline $144-4$ & ISF & $x x$ & $x$ & $x$ & & & & $x x$ & $x$ & & $x$ \\
\hline $144-7$ & IF & $x x$ & $x x$ & $\mathrm{xx}$ & $x$ & & & $\mathrm{xx}$ & $x$ & & \\
\hline $144-8$ & Veio de qtz + PHem & & & & & $x x$ & & $x x$ & $x$ & $x$ & \\
\hline $144-9$ & IT (contato com veio-) & $x$ & $x$ & & & $x x$ & & $x x$ & $x$ & & \\
\hline $144-10$ & IT & $x x$ & $x$ & & & & & $x x$ & $x$ & & \\
\hline $152-2$ & IT & $x x$ & $x x$ & & & & & $x x$ & $x x$ & & \\
\hline $152-4$ & Veio de qtz + PHem & $x$ & & & & $x x$ & & $x x$ & $x$ & & \\
\hline $152-5$ & IT & $x x$ & & & & & & $x x$ & & & \\
\hline $195-1$ & IF & $x x$ & $x x$ & & & & & $x x$ & $x x$ & & \\
\hline $195-3$ & ISF & $x x$ & $x$ & $x$ & & & & $x x$ & $x$ & & \\
\hline
\end{tabular}

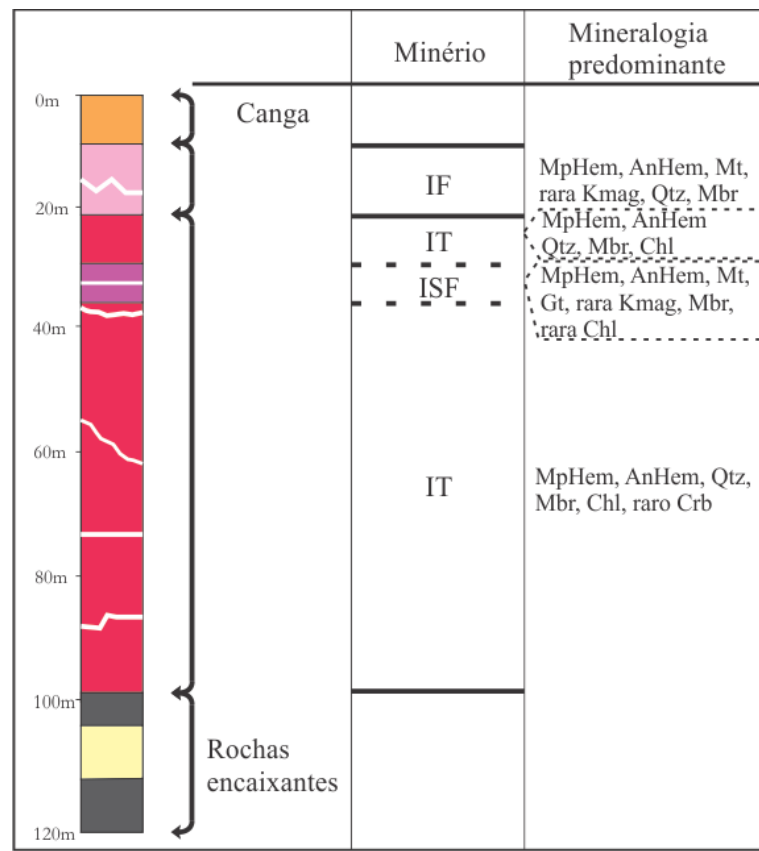

Figura 4. Perfil de intemperismo, mostrando os tipos de minério e mineralogia típica de cada tipo.

\subsection{Itabirito}

O itabirito apresenta microbandamento característico, marcado pela alternância de bandas constituídas essencialmente por quartzo e óxidos de ferro, com porções ricas em mica (Tab. 1). Exibe granulação fina a média e textura predominantemente granoblástica, com lentes ou até mesmo bandas de quartzo granoblástico, porosas ou não.

Ao microscópio, cristais de quartzo apresentam granulação variando em média de $0,04 \mathrm{~mm}$ a 1,00mm (Fig. 5-A). Quando associados às bandas de minerais opacos, os cristais são alongados, de granulação variando de $0,01 \mathrm{~mm}$ a $1,50 \mathrm{~mm}$ em média. Mica branca pode ocorrer como cristais de hábito acicular ou placóide (Fig. 5-B), variando de $0,005 \mathrm{~mm}$ a $0,60 \mathrm{~mm}$, junto ao quartzo e aos minerais opacos, podendo ainda estar inclusos nos cristais. Cristais aciculares de clorita (Fig. 5-C), de cor verde claro acinzentado, ocorrem em geral com granulação de $0,02 \mathrm{~mm}$ a $0,15 \mathrm{~mm}$, também associados à hematita. Cristais de hematita de diferentes texturas podem ser reconhecidos, sendo os cristais microlamelares a variedade mais comum, típicos nas bandas opacas e esporádicos nas bandas ricas em quartzo, em geral subédricos, de granulação fina a grossa, 0,005 mm a 0,42 mm (Fig. 5D e Tab. 2), com sobrecrescimento dos cristais grossos sobre os finos. Quando associados aos aglomerados de hematita anédrica e à martita subordinada (Tab. 1) tendem a formar bandas de espessuras variadas. Quando inclusos nos cristais de quartzo, a granulação dos cristais de hematita microlamelar varia de menores que $0,005 \mathrm{~mm}$ a 0,05 mm. Aglomerados anédricos e porosos (Fig. 5-E e Tab. 2) são prováveis cristais lobados de martita em que o limite original dos pseudomorfos de magnetita está obliterado. Tais aglomerados variam de $0,28 \mathrm{~mm}$ a $0,60 \mathrm{~mm}$, podendo chegar a $1,60 \mathrm{~mm}$, são arredondados ou alongados e sobrecrescidos pelos cristais de hematita microlamelar. Cristais de martita ocorrem de forma dispersa pela rocha, como cristais subédricos, de granulação entre $0,06 \mathrm{~mm}$ e $0,28 \mathrm{~mm}$, em média (Fig. 5-F) sendo também sobrecrescidos pelos cristais de hematita microlamelar e pelos aglomerados de hematita anédrica. 


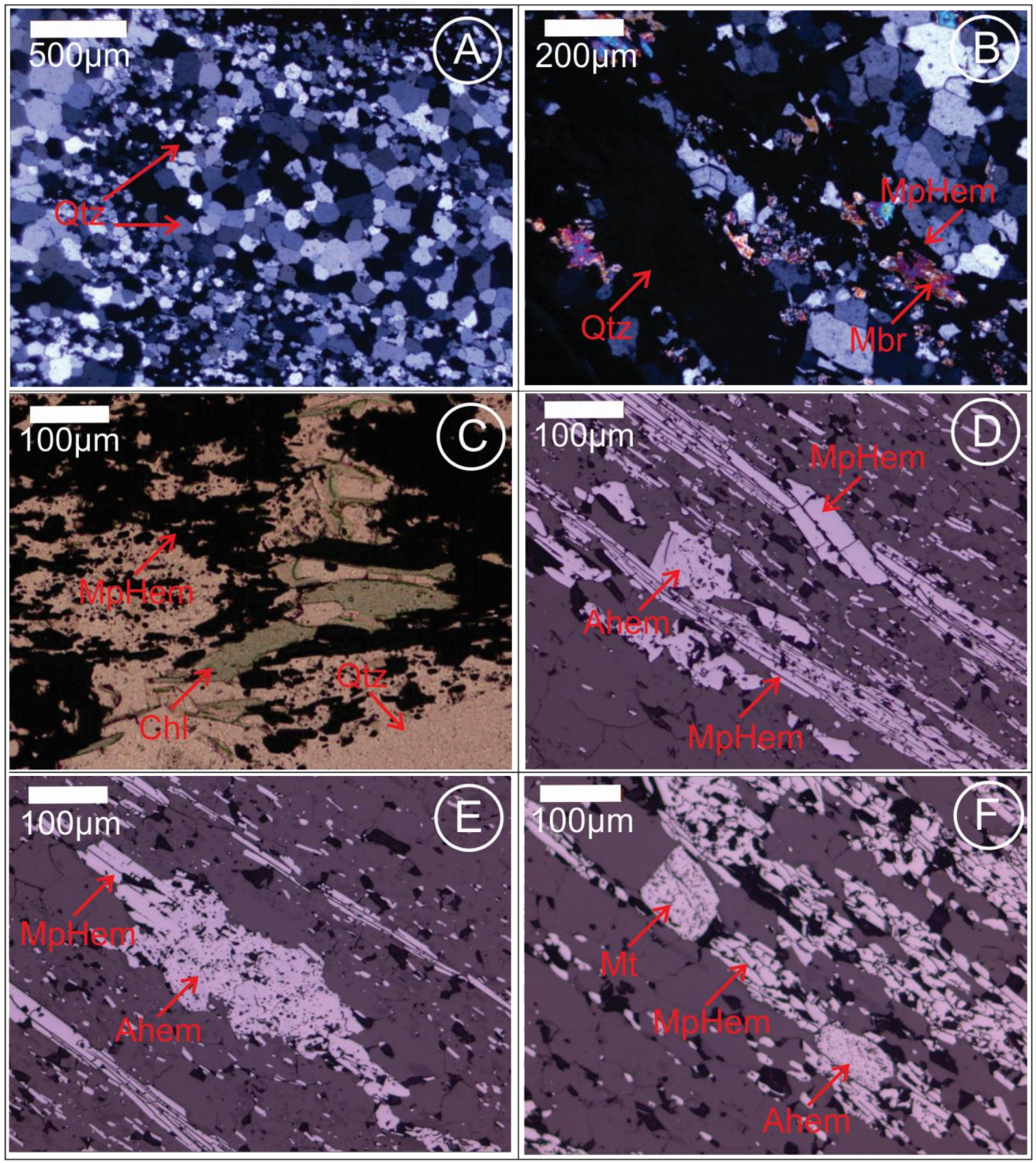

Figura 5. Fotomicrografias mostrando (A): Textura geral das bandas quartzosas, com variação da granulação e ausência de orientação mineral. Luz transmitida, nicóis cruzados, aumento 25X; (B): Cristais de mica branca associados aos cristais de hematita microlamelares. Luz transmitida, nicóis cruzados (50X); (C): Cristais de clorita junto a cristais de hematita. Luz transmitida, nicóis paralelos (100X); (D): Cristais de hematita microlamelar formando bandas. Luz refletida, nicóis paralelos (100X); (E): Aglomerado anédrico de hematita e cristais de hematita microlamelar em luz refletida, nicóis paralelos. Luz refletida, nicóis paralelos (100X); (F): Cristal de martita e glomerado anédrico de hematita junto a cristais de hematita microlamelar. Luz refletida, nicóis paralelos (100X). 
Tabela 2. Tipos de óxidos de ferro classificados com base na definição de Hagemann et al. (2008).

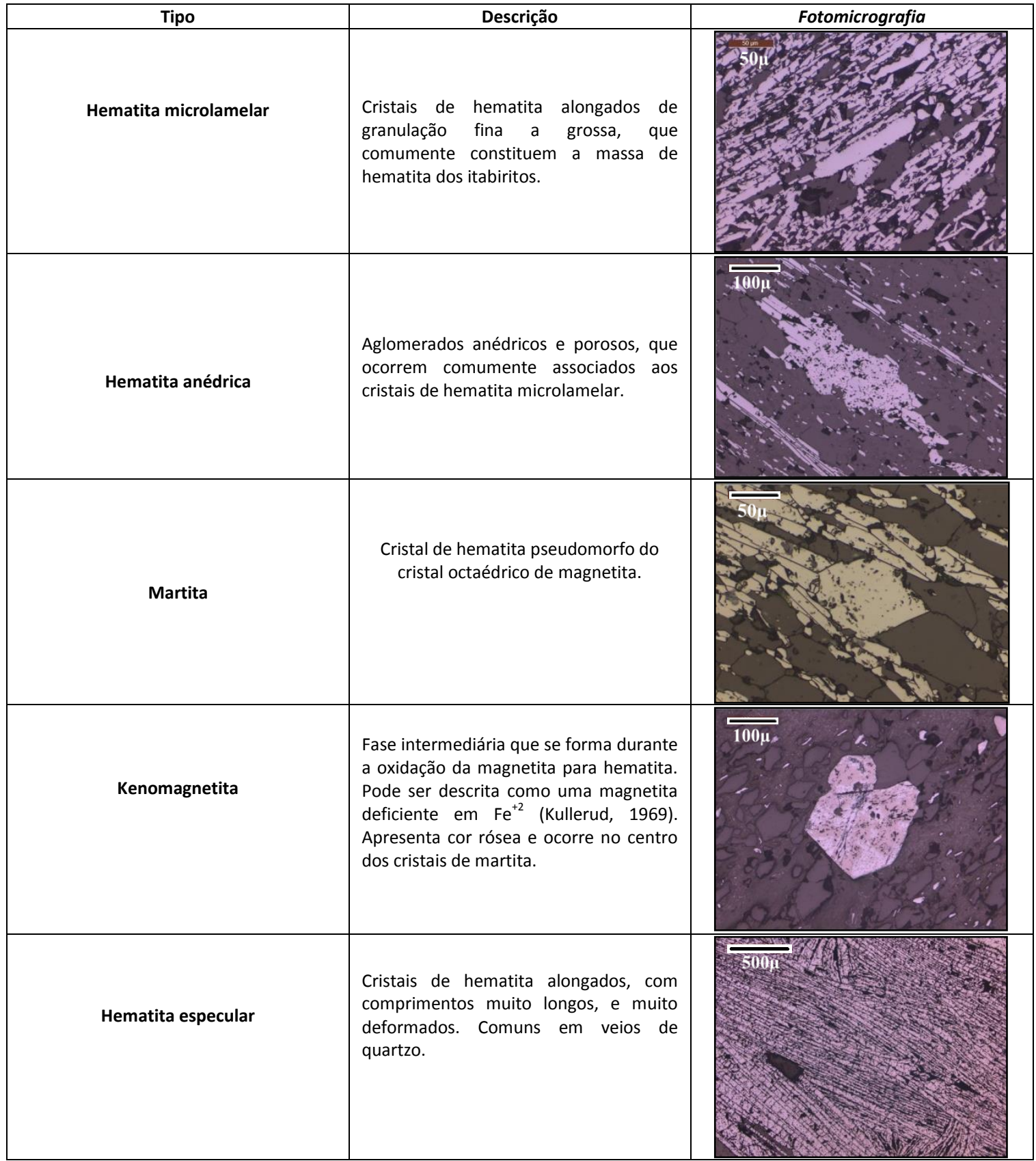

\section{Itabirito Semifriável}

O itabirito semifriável diferencia-se do IT por conter maior quantidade de mica branca, principalmente nas bandas hematíticas, deixando a rocha com brilho sedoso em algumas porções e é comumente magnético. Ao microscópio é mais rico em cristais de martita que o IT, de granulação entre $0,08 \mathrm{~mm}$ e $0,40 \mathrm{~mm}$, em média. Estes ocorrem associados à hematita microlamelar (Fig. 6-A; Tab. 2), podendo estar presentes em poros (Fig. 6-B). Relictos de cor rósea-marrom, característicos de kenomagnetita, são comumente observados nos núcleos de martita (Fig. 6-C e Tab. 2).
Goethita/limonita (Fig. 6-D) ocorre como uma massa amorfa entre os cristais de hematita microlamelar e os de minerais translúcidos.

\section{Itabirito friável}

O itabirito friável consiste em um material fragmentado a pulverulento, com porções ricas em quartzo e mica intercaladas com óxidos de ferro. Amostras pulverulentas podem ser magnéticas. Microscopicamente, apresenta muitos poros nas bandas de minerais transparentes (Fig. 7-A). Mineralogicamente mostra-se semelhante aos outros tipos de itabirito com maior proporção de mica (Fig. 7-B). 

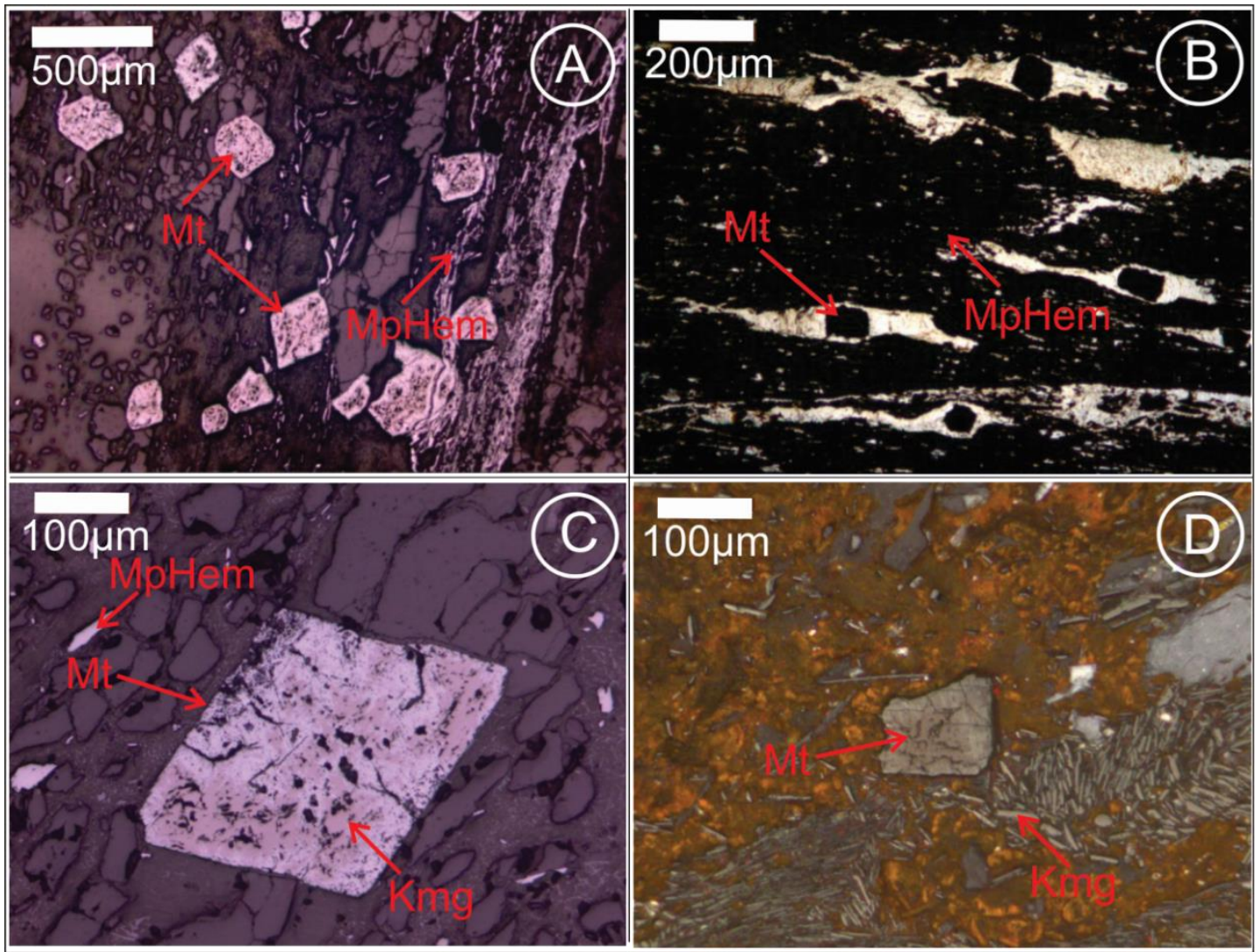

Figura 6. Fotomicrografias (A): Aspecto geral da lâmina contendo cristais de martita com resquícios de kenomagnetita e cristais microlamelares de hematita. Luz refletida, nicóis paralelos (25X); (B): Cristais de martita localizados nos poros do itabirito semifriável. Luz transmitida, nicóis paralelos (50X); (C): Cristal de martita contendo relictos de kenomagnetita. Luz refletida, nicóis paralelos (100X); (D): Ocorrência de goethita em porção deformada do itabirito semifriável onde o bandamento é destruído. Luz refletida, nicóis cruzados (100X).

\subsection{Veios de quartzo com hematita especular}

Os veios são compostos essencialmente por quartzo e hematita, com textura granoblástica. Em geral os cristais de quartzo são anédricos e têm granulação muito variada. Quando associados aos cristais de hematita, apresentam-se com granulação fina, $0,02 \mathrm{~mm}$ a $0,40 \mathrm{~mm}$ em média, orientados, fazendo contatos retos e côncavo-convexos entre si. Já os cristais grossos chegam a cerca de $2,00 \mathrm{~mm}$, podendo ser maiores que o retículo do microscópio e apresentarem extinção ondulante.

Cristais aciculares e placóides de mica branca, de

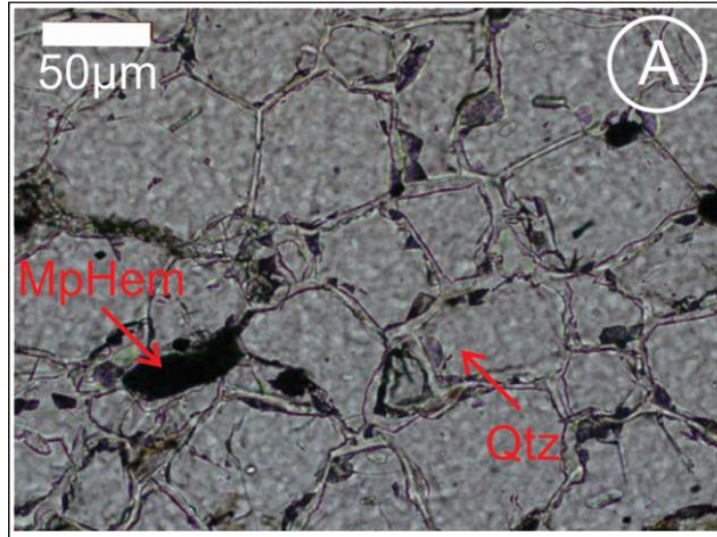

granulação entre $0,04 \mathrm{~mm}$ a $2,00 \mathrm{~mm}$, são alongados e associados à hematita, assim como cristais de gibsita anédricos e deformados de granulação chegando a 1,20mm (Fig. 8-A). Carbonato foi identificado em apenas uma das lâminas de veios (Fig. 8-B).

A hematita ocorre majoritariamente como cristais especulares (Fig. 8-C e Tab. 2), muito orientados e fraturados, e em menor frequência como aglomerados de hematita anédrica e cristais microlamelares (Fig. 8-D), de granulação variando de $0,10 \mathrm{~mm}$ a $0,40 \mathrm{~mm}$.

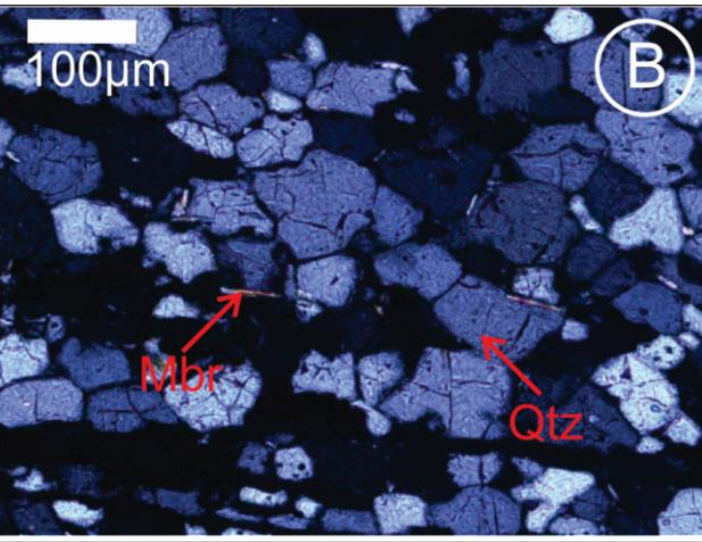

Figura 7. Fotomicrografias mostrando (A): Porosidade entre os cristais de quartzo. Luz transmitida, nicóis paralelos (200X); (B): Cristais de mica branca aciculares entre os cristais de quartzo. Luz transmitida, nicóis cruzados (100X). 


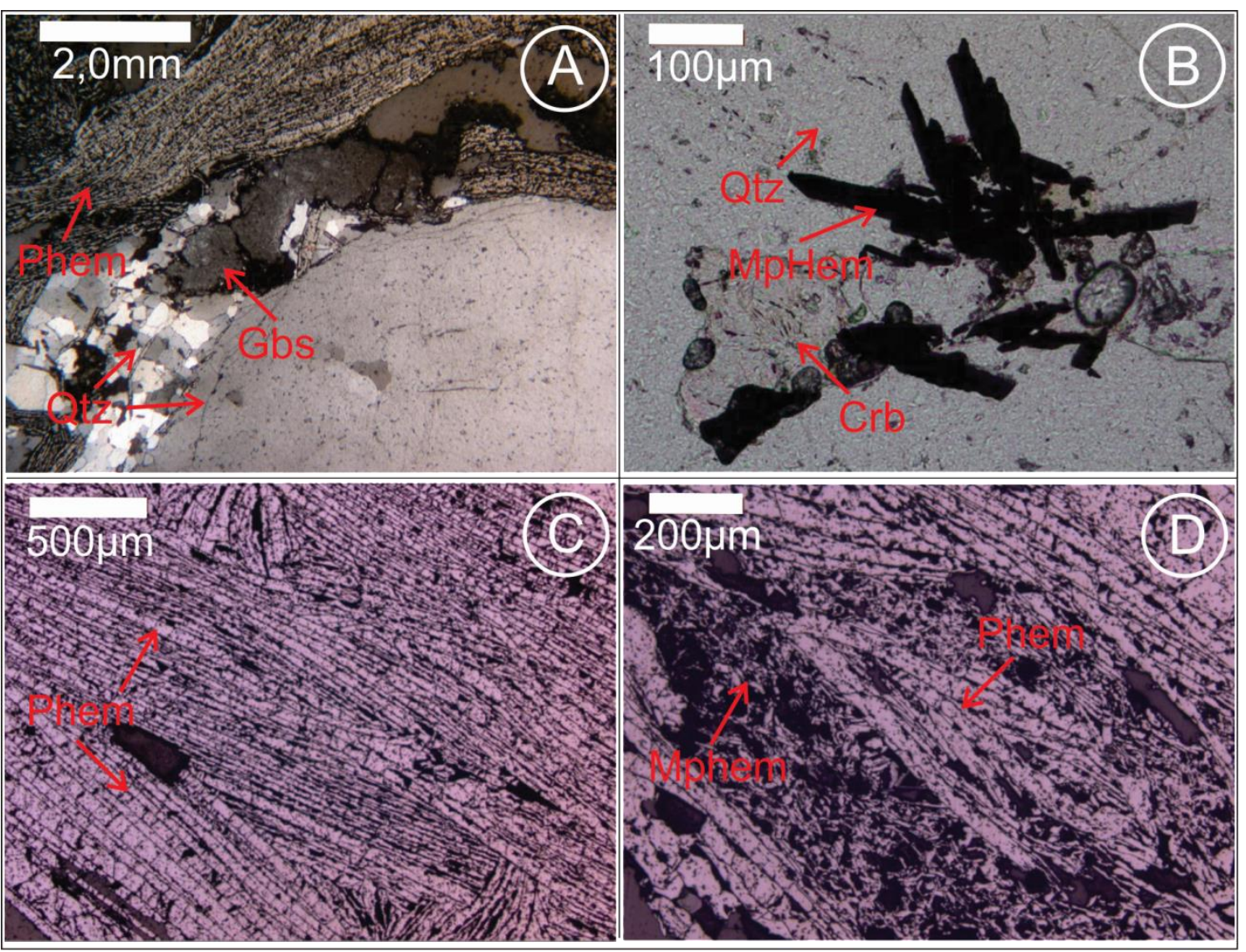

Figura 8. (A): Cristal de gibsita junto a cristais de hematita lamelar e quartzo. Luz transmitida, nicóis cruzados (25X); (B): Cristal de carbonato junto a cristais de hematita microlamelar. Luz transmitida, nicóis paralelos (100X); Cristais longos de hematita especular. Luz refletida, nicóis paralelos (25X); (C): Cristais longos de hematita lamelar. Luz refletida, nicóis paralelos (25X); (D): Cristais lamelares de hematita junto aos cristais microlamelares. Luz refletida, nicóis paralelos (50X).

\section{GEOQUÍMICA}

As amostras analisadas foram selecionadas para abranger a maior variedade possível dos tipos de óxidos de ferro existentes, com base em amostras de mão e feições microscópicas, incluindo IT, IF, ISF e hematita especularítica em veio de quartzo. A Tab. 3 mostra os resultados das análises químicas de rocha total.

\subsection{Elementos Maiores}

Conforme a Tab. 3, os componentes principais são $\mathrm{SiO}_{2}$ e $\mathrm{Fe}_{2} \mathrm{O}_{3}$ com conteúdo menor de $\mathrm{CaO}, \mathrm{MgO}$, $\mathrm{MnO}, \mathrm{Al}_{2} \mathrm{O}_{3}, \mathrm{~K}_{2} \mathrm{O}, \mathrm{TiO}_{2}$ e $\mathrm{P}_{2} \mathrm{O}_{5}$. As maiores variações nos teores de $\mathrm{SiO}_{2}$ e $\mathrm{Fe}_{2} \mathrm{O}_{3}$ ocorrem no IT, seguido pelos ISF e IF. Na Fig. 9 são mostradas as proporções dos elementos maiores em itabirito com diferentes graus de intemperismo, e nas Fig. 10-A, B e C separadamente para cada tipo de itabirito. Especularita em veio de quartzo também é apresentada na Fig. 10-D, a título de comparação.

Os conteúdos de $\mathrm{CaO}(\leq 0,14 \mathrm{wt} \%), \mathrm{MgO}$ ( $\leq$ $0,04 w t \%), \mathrm{MnO}(\leq 0,21 w t \%), \mathrm{Al}_{2} \mathrm{O}_{3}(\leq 0,94 w t \%), \mathrm{K}_{2} \mathrm{O}$ $(\leq 0,27 w t \%), \mathrm{TiO}_{2} \quad(\leq 0,05 w t \%)$ e $\mathrm{P}_{2} \mathrm{O}_{5}(\leq 0,11 w t \%)$ são baixos em todas as amostras analisadas.

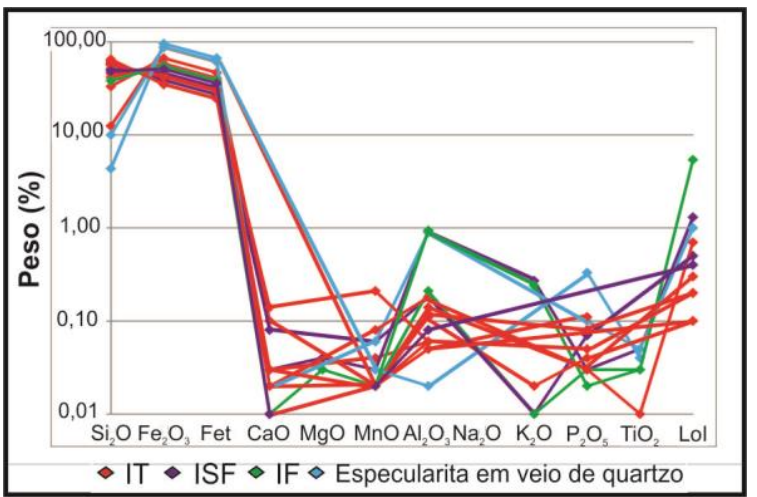

Figura 9. Diagrama de concentração dos elementos maiores.

Destaca-se que as maiores concentrações de Al2O3 encontram-se nas amostras de ISF, IF e hematita especularita em veio de quartzo, e o P2O5, apesar de estar em concentrações baixas ( $\leq$ $0,33 w t \%)$, está presente em todos os tipos de amostras (vide Tab. 3 e Fig. 10). A concentração de K2O é maior que o limite de detecção $(0,01 w t \%)$ em apenas uma amostra de IT com teor de 0,02wt\%, chegando a $0,27 w t \%$ no ISF e $0,24 w t \%$ no IF (Figs. 14-A, B e C e Tab. 3). Já $\mathrm{CaO}$ e $\mathrm{MnO}$ foram detectados em todas as amostras, também apresentando teores muito baixos, entre 0,01wt\% e $0,14 w t \%$ e $0,02 w t \%$ e $0,21 w t \%$, respectivamente no 
IT, e nos ISF e IF. Tais concentrações chegam a $0,08 w t \%$ de $\mathrm{CaO}$ e $0,06 w t \%$ de $\mathrm{MnO}$ no primeiro e $0,01 w t \%$ e 0,02wt\%, respectivamente para o último. $\mathrm{O} \mathrm{MgO}$ foi encontrado com teores maiores que o limite de detecção $(0,01 w t \%)$ apenas em uma amostra de ISF (FD144-4), e uma de IF (FD195-1) (Tab. 3), ambas com concentrações baixas, de $0,04 w t \%$ e de $0,03 w t \%$, respectivamente

Tabela 3. Resultado de análise química de itabiritos.

\begin{tabular}{|c|c|c|c|c|c|c|c|c|c|c|c|c|c|c|c|}
\hline FD: & 201-1 & 201-2 & 201-3 & 201-4 & 201-7 & $144-4$ & $144-7$ & $144-8$ & $144-9$ & 144-10 & $152-2$ & $152-4$ & $152-5$ & 195-1 & 195-3 \\
\hline Rocha (wt\%) & IT & ISF & IT & IT & IT & ISF & IF & \begin{tabular}{c|} 
PHem \\
em veio
\end{tabular} & IT & IT & IT & \begin{tabular}{|c|}
$\begin{array}{c}\text { PHem } \\
\text { em veio }\end{array}$ \\
\end{tabular} & IT & IF & ISF \\
\hline $\mathrm{SiO}_{2}$ & 33,10 & 60,31 & 12,45 & 41,47 & \begin{tabular}{|l|}
64,83 \\
\end{tabular} & 50,95 & 57,29 & 9,96 & 45,73 & 56,05 & 57,42 & 4,34 & 63,64 & 38,08 & 48,44 \\
\hline $\mathrm{Al}_{2} \mathrm{O3}$ & 0,06 & 0,18 & 0,14 & 0,05 & 0,06 & 0,93 & 0,21 & 0,89 & 0,11 & 0,06 & 0,12 & 0,02 & 0,18 & 0,94 & 0,08 \\
\hline $\mathrm{Fe}_{2} \mathrm{O}_{3}$ & 66,66 & 38,68 & 87,01 & 58,29 & 34,75 & 46,27 & 42,62 & 87,82 & 53,90 & 43,39 & 42,05 & 95,54 & 35,28 & 55,19 & 51,03 \\
\hline $\mathrm{Fe}_{\text {Total }}$ & 46,63 & 27,06 & 60,86 & 40,77 & 24,31 & 32,37 & 29,81 & 61,43 & 37,70 & 30,35 & 29,41 & 66,83 & 24,68 & 38,60 & 35,70 \\
\hline $\mathrm{MgO}$ & $<0,01$ & $<0,01$ & $<0,01$ & $<0,01$ & $<0,01$ & 0,04 & $<0,01$ & $<0,01$ & $<0,01$ & $<0,01$ & $<0,01$ & $<0,01$ & $<0,01$ & 0,03 & $<0,01$ \\
\hline $\mathrm{CaO}$ & 0,10 & 0,08 & $<0,01$ & 0,01 & 0,03 & 0,03 & 0,01 & 0,02 & 0,03 & 0,14 & 0,03 & $<0,01$ & 0,02 & 0,01 & 0,01 \\
\hline $\mathrm{Na}_{2} \mathrm{O}$ & $<0,01$ & $<0,01$ & $<0,01$ & $<0,01$ & $<0,01$ & $<0,01$ & $<0,01$ & $<0,01$ & $<0,01$ & $<0,01$ & $<0,01$ & $<0,01$ & $<0,01$ & $<0,01$ & $<0,01$ \\
\hline $\mathrm{K}_{2} \mathrm{O}$ & $<0,01$ & 0,01 & $<0,01$ & $<0,01$ & $<0,01$ & 0,27 & 0,01 & $<0,01$ & 0,02 & $<0,01$ & $<0,01$ & $<0,01$ & $<0,01$ & 0,24 & $<0,01$ \\
\hline $\mathrm{TiO}_{2}$ & $<0,01$ & $<0,01$ & $<0,01$ & $<0,01$ & $<0,01$ & 0,05 & 0,03 & 0,05 & $<0,01$ & $<0,01$ & $<0,01$ & 0,04 & 0,01 & 0,03 & $<0,01$ \\
\hline $\mathrm{P}_{2} \mathrm{O}_{5}$ & $<0,01$ & 0,07 & 0,03 & $<0,01$ & 0,05 & 0,03 & 0,03 & 0,10 & 0,04 & 0,11 & 0,08 & 0,33 & 0,03 & 0,02 & $<0,01$ \\
\hline MnO & 0,02 & 0,06 & 0,02 & 0,02 & 0,04 & 0,03 & 0,02 & 0,06 & 0,02 & 0,21 & 0,02 & 0,03 & 0,08 & 0,02 & 0,02 \\
\hline $\mathrm{Cr}_{2} \mathrm{O}_{3}$ & $<0,002$ & 0,011 & $<0,002$ & 0,003 & $<0,002$ & 0,005 & 0,005 & 0,025 & 0,004 & 0,003 & 0,002 & 0,002 & 0,002 & 0,006 & $<0,002$ \\
\hline LOI & 0,0 & 0,5 & 0,3 & 0,1 & 0,2 & 1,3 & $-0,3$ & 1,0 & 0,1 & 0,0 & 0,2 & $-0,1$ & 0,7 & 5,4 & 0,4 \\
\hline Sum & 99,92 & 99,93 & 99,91 & 99,91 & 99,94 & 99,93 & 99,93 & 99,89 & 99,93 & 99,94 & 99,88 & 99,96 & 99,93 & 99,90 & 99,93 \\
\hline Sc (ppm) & 1 & $<1$ & 1 & $<1$ & $<1$ & 3 & $<1$ & 3 & $<1$ & $<1$ & $<1$ & 1 & 1 & 2 & $<1$ \\
\hline $\mathrm{Ba}$ & 2 & 36 & 3 & 3 & 65 & 81 & 34 & 13 & 37 & 17 & 548 & 1 & 142 & 263 & 10 \\
\hline $\mathrm{Be}$ & $<1$ & $<1$ & $<1$ & $<1$ & 1 & $<1$ & $<1$ & $<1$ & $<1$ & 2 & 2 & $<1$ & $<1$ & 2 & $<1$ \\
\hline Co & 0,08 & 2,7 & 0,3 & 0,9 & 1,1 & 1,4 & 1,6 & 2,5 & 1,1 & 35 & 0,4 & 0,5 & 1,5 & 0,6 & 0,9 \\
\hline Cs & $<0,1$ & 0,1 & $<0,1$ & $<0,1$ & $<0,1$ & 0,1 & $<0,1$ & $<0,1$ & $<0,1$ & $<0,1$ & $<0,1$ & $<0,1$ & $<0,1$ & 0,1 & 0,3 \\
\hline Ga & 1,7 & 2,3 & 2,1 & 1,2 & 1,4 & 2,1 & 1,4 & 3,1 & 1,6 & 1,0 & 0,5 & 2,9 & 1,1 & 1,5 & 1,1 \\
\hline $\mathrm{Hf}$ & $<0,1$ & 0,1 & $<0,1$ & $<0,1$ & $<0,1$ & 0,2 & $<0,1$ & 0,4 & $<0,1$ & $<0,1$ & $<0,1$ & $<0,1$ & $<0,1$ & 0,1 & 0,1 \\
\hline $\mathrm{Nb}$ & $<0,1$ & $<0,1$ & $<0,1$ & $<0,1$ & $<0,1$ & 0,7 & 0,2 & 1,3 & 0,2 & $<0,1$ & 0,1 & 0,9 & 0,1 & 0,4 & 0,9 \\
\hline $\mathbf{R b}$ & $<0,1$ & 0,8 & $<0,1$ & $<0,1$ & 0,3 & 5,4 & 0,6 & $<0,1$ & 0,8 & 0,3 & 0,1 & $<0,1$ & $<0,1$ & 5,7 & 1,3 \\
\hline Sn & $<1$ & $<1$ & $<1$ & $<1$ & $<1$ & $<1$ & $<1$ & $<1$ & $<1$ & $<1$ & $<1$ & $<1$ & $<1$ & $<1$ & $<1$ \\
\hline $\mathrm{Sr}$ & 2,2 & 1,3 & 1,4 & 1,8 & 1,1 & 6,9 & 1,2 & 4,2 & 1,6 & 1,8 & 4,9 & 0,9 & 1,9 & 2,4 & 0,9 \\
\hline $\mathrm{Ta}$ & $<0,1$ & 0,1 & $<0,1$ & $<0,1$ & $<0,1$ & $<0,1$ & $<0,1$ & 0,2 & $<0,1$ & $<0,1$ & $<0,1$ & $<0,1$ & $<0,1$ & $<0,1$ & 1,2 \\
\hline Th & $<0,2$ & $<0,2$ & $<0,2$ & $<0,2$ & $<0,2$ & 0,8 & 0,3 & 0,8 & $<0,2$ & $<0,2$ & $<0,2$ & $<0,2$ & 0,2 & 0,5 & $<0,2$ \\
\hline$U$ & 0,8 & 0,6 & 1,5 & 0,2 & 0,7 & 1,2 & 1,9 & 7,3 & 0,4 & 0,6 & 0,4 & $<0,1$ & 1,5 & 0,5 & $<0,1$ \\
\hline $\mathbf{v}$ & 39 & 75 & 296 & 61 & 24 & 29 & 98 & 206 & 84 & 24 & 46 & 103 & 50 & 43 & 48 \\
\hline $\mathbf{w}$ & 10,4 & 10,3 & 6,2 & 3,0 & 4,4 & 3,3 & 2,7 & 12,4 & 2,9 & 3,3 & 2,7 & 0,9 & 2,4 & 3,6 & 3,4 \\
\hline $\mathrm{Zr}$ & 2,0 & 3,1 & 5,8 & 3,6 & 2,1 & 10,3 & 4,9 & 25,3 & 4,8 & 1,7 & 2,6 & 1,4 & 7,6 & 10,1 & 1,7 \\
\hline $\mathrm{Ag}$ & 0,1 & $<0,1$ & $<0,1$ & $<0,1$ & $<0,1$ & $<0,1$ & $<0,1$ & $<0,1$ & $<0,1$ & $<0,1$ & $<0,1$ & $<0,1$ & $<0,1$ & $<0,1$ & $<0,1$ \\
\hline As & 1,6 & 2,5 & 1,3 & 0,8 & 1,6 & 1,2 & 1,3 & 6,1 & 0,7 & 3,4 & 1,9 & 1,0 & 3,3 & 1,7 & 0,9 \\
\hline $\mathrm{Bi}$ & $<0,1$ & $<0,1$ & $<0,1$ & $<0,1$ & $<0,1$ & $<0,1$ & $<0,1$ & $<0,1$ & $<0,1$ & $<0,1$ & $<0,1$ & $<0,1$ & $<0,1$ & $<0,1$ & $<0,1$ \\
\hline Cd & $<0,1$ & $<0,1$ & $<0,1$ & $<0,1$ & $<0,1$ & $<0,1$ & $<0,1$ & $<0,1$ & $<0,1$ & $<0,1$ & $<0,1$ & $<0,1$ & $<0,1$ & $<0,1$ & $<0,1$ \\
\hline $\mathrm{Cu}$ & 58,4 & 17,7 & 15,7 & 9,9 & 9,6 & 20,1 & 12,3 & 14,3 & 9,2 & 8,1 & 30,2 & 19,2 & 16,5 & 16,1 & 11,3 \\
\hline $\mathrm{Hg}$ & $<0,1$ & $<0,01$ & $<0,01$ & 0,01 & $<0,01$ & 0,01 & $<0,01$ & $<0,01$ & $<0,01$ & $<0,01$ & $<0,01$ & $<0,01$ & $<0,1$ & $<0,1$ & 0,01 \\
\hline Mo & 2,9 & 1,8 & 2,0 & 1,9 & 2,2 & 0,9 & 1,3 & 0,9 & 0,9 & 0,9 & 1,0 & 1,4 & 0,8 & 0,9 & 0,6 \\
\hline $\mathrm{Ni}$ & 2,2 & 20,5 & 1,0 & 2,0 & 7,0 & 3,8 & 5,7 & 10,3 & 4,3 & 6,8 & 1,8 & 2,5 & 3,1 & 1,5 & 1,7 \\
\hline $\mathrm{Pb}$ & 2,1 & 1,6 & 2,0 & 1,2 & 0,8 & 2,2 & 2,1 & 2,6 & 1,3 & 1,4 & 2,8 & 1,4 & 2,9 & 1,5 & 1,2 \\
\hline Sb & 1,9 & 0,8 & 1,1 & 0,8 & 0,5 & 0,3 & 0,5 & 0,7 & 1,0 & 0,8 & 0,3 & 0,4 & 0,4 & 0,2 & 0,3 \\
\hline Se & $<0,5$ & $<0,5$ & $<0,5$ & $<0,5$ & $<0,5$ & $<0,5$ & $<0,5$ & $<0,5$ & $<0,5$ & $<0,5$ & $<0,5$ & $<0,5$ & $<0,5$ & $<0,5$ & $<0,5$ \\
\hline $\mathbf{T}$ & $<0,1$ & $<0,1$ & $<0,1$ & $<0,1$ & $<0,1$ & $<0,1$ & $<0,1$ & $<0,1$ & $<0,1$ & $<0,1$ & $<0,1$ & $<0,1$ & $<0,1$ & $<0,1$ & $<0,1$ \\
\hline $\mathrm{Zn}$ & 3 & 9 & 9 & 2 & 7 & 10 & 12 & 22 & 4 & 6 & 17 & 8 & 7 & 9 & 5 \\
\hline $\mathrm{Y}$ & 7,8 & 7,3 & 8,9 & 4,6 & 1,4 & 19,1 & 4,9 & 45,0 & 2,8 & 3,9 & 3,7 & 0,2 & 4,0 & 5,5 & 2,6 \\
\hline La & 1,2 & 1,0 & 0,9 & 0,8 & 0,4 & 6,9 & 2,6 & 20,6 & 1,0 & 0,7 & 1,2 & 0,5 & 1,6 & 2,0 & 1,2 \\
\hline $\mathrm{Ce}$ & 2,5 & 1,6 & 1,5 & 1,1 & 0,6 & 11,8 & 5,0 & 35,2 & 1,4 & 1,3 & 2,3 & 0,2 & 3,6 & 2,7 & 1,9 \\
\hline $\mathrm{Pr}$ & 0,26 & 0,25 & 0,17 & 0,12 & 0,07 & 1,46 & 0,53 & 3,82 & 0,21 & 0,18 & 0,27 & $<0,02$ & 0,41 & 0,31 & 0,24 \\
\hline $\mathrm{Nd}$ & 0,8 & 1,4 & 1,2 & 1,0 & $<0.3$ & 6,6 & 2,4 & 15,3 & 0,8 & 0,8 & 1,3 & 0,3 & 1,8 & 1,2 & 1,1 \\
\hline $\mathrm{Sm}$ & 0,23 & 0,25 & 0,16 & 0,05 & $<0,05$ & 0,97 & 0,36 & 2,74 & 0,21 & 0,16 & 0,19 & $<0,05$ & 0,36 & 0,2 & 0,16 \\
\hline $\mathrm{Eu}$ & 0,11 & 0,14 & 0,12 & 0,06 & 0,02 & 0,41 & 0,15 & 1,23 & 0,11 & 0,09 & 0,06 & $<0,02$ & 0,22 & 0,10 & 0,09 \\
\hline Gd & 0,48 & 0,46 & 0,45 & 0,24 & 0,07 & 1,61 & 0,59 & 4,45 & 0,41 & 0,31 & 0,29 & 0,08 & 0,98 & 0,44 & 0,46 \\
\hline Tb & 0,08 & 0,08 & 0,08 & 0,03 & 0,01 & 0,27 & 0,08 & 0,68 & 0,06 & 0,05 & 0,06 & $<0,01$ & 0,17 & 0,09 & 0,05 \\
\hline Dy & 0,56 & 0,64 & 0,74 & 0,36 & 0,08 & 1,95 & 0,50 & 4,84 & 0,40 & 0,46 & 0,52 & $<0,05$ & 1,24 & 0,56 & 0,40 \\
\hline Ho & 0,14 & 0,16 & 0,17 & 0,10 & 0,05 & 0,47 & 0,13 & 1,08 & 0,06 & 0,09 & 0,10 & $<0,02$ & 0,02 & 0,15 & 0,08 \\
\hline $\mathrm{Er}$ & 0,76 & 0,58 & 0,71 & 0,39 & 0,13 & 1,60 & 0,40 & 3,27 & 0,17 & 0,33 & 0,38 & $<0,03$ & 0,49 & 0,58 & 0,20 \\
\hline $\mathrm{Tm}$ & 0,08 & 0,11 & 0,10 & 0,06 & 0,02 & 0,24 & 0,05 & 0,45 & 0,02 & 0,05 & 0,05 & $<0,01$ & 0,04 & 0,07 & 0,01 \\
\hline $\mathrm{Yb}$ & 0,55 & 0,88 & 0,82 & 0,50 & 0,20 & 1,71 & 0,43 & 3,01 & 0,10 & 0,37 & 0,37 & $<0,05$ & 0,26 & 0,51 & 0,30 \\
\hline Lu & 0,10 & 0,14 & 0,14 & 0,09 & 0,02 & 0,27 & 0,08 & 0,45 & 0,01 & 0,04 & 0,07 & $<0,01$ & 0,03 & 0,09 & 0,03 \\
\hline $\mathrm{Au}(\mathrm{ppb})$ & 2,4 & 1,8 & $<0,5$ & 2,6 & $<0,5$ & $<0,5$ & 0,9 & 1,0 & 1,2 & $<0,5$ & $<0,5$ & 2,4 & 1,5 & 2,1 & $<0,5$ \\
\hline ¿ETR & 7,85 & 7,69 & 7,26 & 4,90 & 1,67 & 36,26 & 13,30 & 97,12 & 4,96 & 4,93 & 7,16 & 1,08 & 11,40 & 9,00 & 6,22 \\
\hline${ }^{a} \mathrm{Pr} / \mathrm{Yb}_{(\mathrm{SN})}$ & 0,15 & 0,09 & 0,07 & 0,077 & 0,11 & 0,27 & 0,39 & 0,41 & 0,67 & 0,16 & 0,23 & - & 0,50 & 0,19 & 0,26 \\
\hline${ }^{b} \mathrm{Eu} / \mathrm{Eu}^{2}{ }_{(\mathrm{SN})}$ & 1,65 & 2,02 & 2,08 & 2,96 & - & 1,64 & 1,79 & 1,84 & 2,01 & 2,06 & 1,15 & - & 1,76 & 1,48 & 2,06 \\
\hline${ }^{\mathrm{c}} \mathrm{Ce} / \mathrm{Ce}{ }^{*}{ }_{(\mathrm{SN})}$ & 1,03 & 0,74 & 0,88 & 0,80 & 0,82 & 0,86 & 0,98 & 0,91 & 0,70 & 0,84 & 0,93 & - & 1,02 & 0,78 & 0,82 \\
\hline $\mathrm{Y} / \mathrm{Ho}$ & \begin{tabular}{|l|}
55,71 \\
\end{tabular} & 45,63 & 52,35 & 46 & 28 & 40,64 & 37,69 & 41,67 & 46,67 & 43,33 & 37 & - & 20 & 36,67 & 32,5 \\
\hline
\end{tabular}




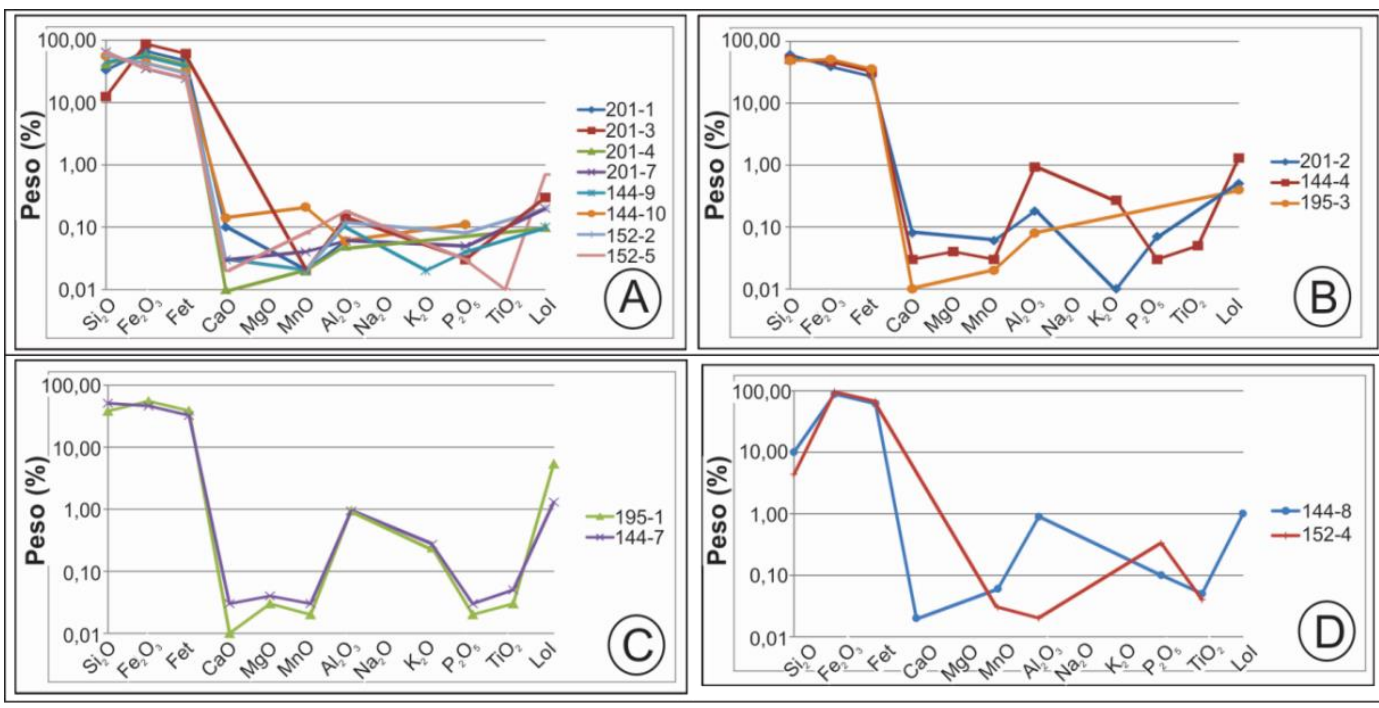

Figura 10. (A) Diagrama de elementos maiores das amostras de itabirito (B) Diagrama de elementos maiores das amostras de itabirito semifriável; (C) Diagrama de elementos maiores das amostras de itabirito friável; (D): Diagrama de elementos maiores das amostras de especularita em veio quartzo.

Todas as amostras de IT apresentaram valores de $\mathrm{TiO}_{2}$ abaixo do limite de deteç̧ão $(0,01 \mathrm{wt} \%)$, sendo observado apenas em uma amostra de ISF (FD144-4) com concentração de 0,05wt\%, nas duas amostras de IF, com 0,03wt\% e as amostras de especularita em veios de quartzo, com 0,04wt\% e 0,05wt\% (Tab. $3)$.

\subsection{Elementos traço}

Os elementos traço são mostrados no diagrama da Fig. 11, de acordo com as concentrações de cada elemento. Já as Fig. 12-A, B, C e D mostram as mesmas concentrações separadas de acordo com cada tipo de rocha.

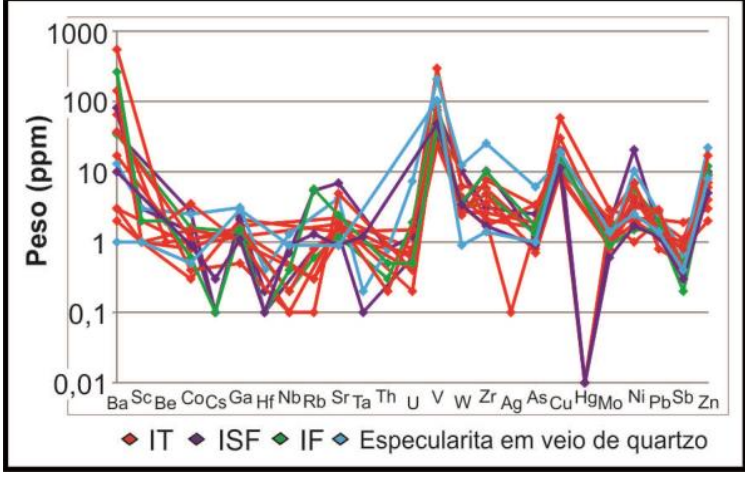

Figura 11. Diagrama de concentração dos elementos traço.

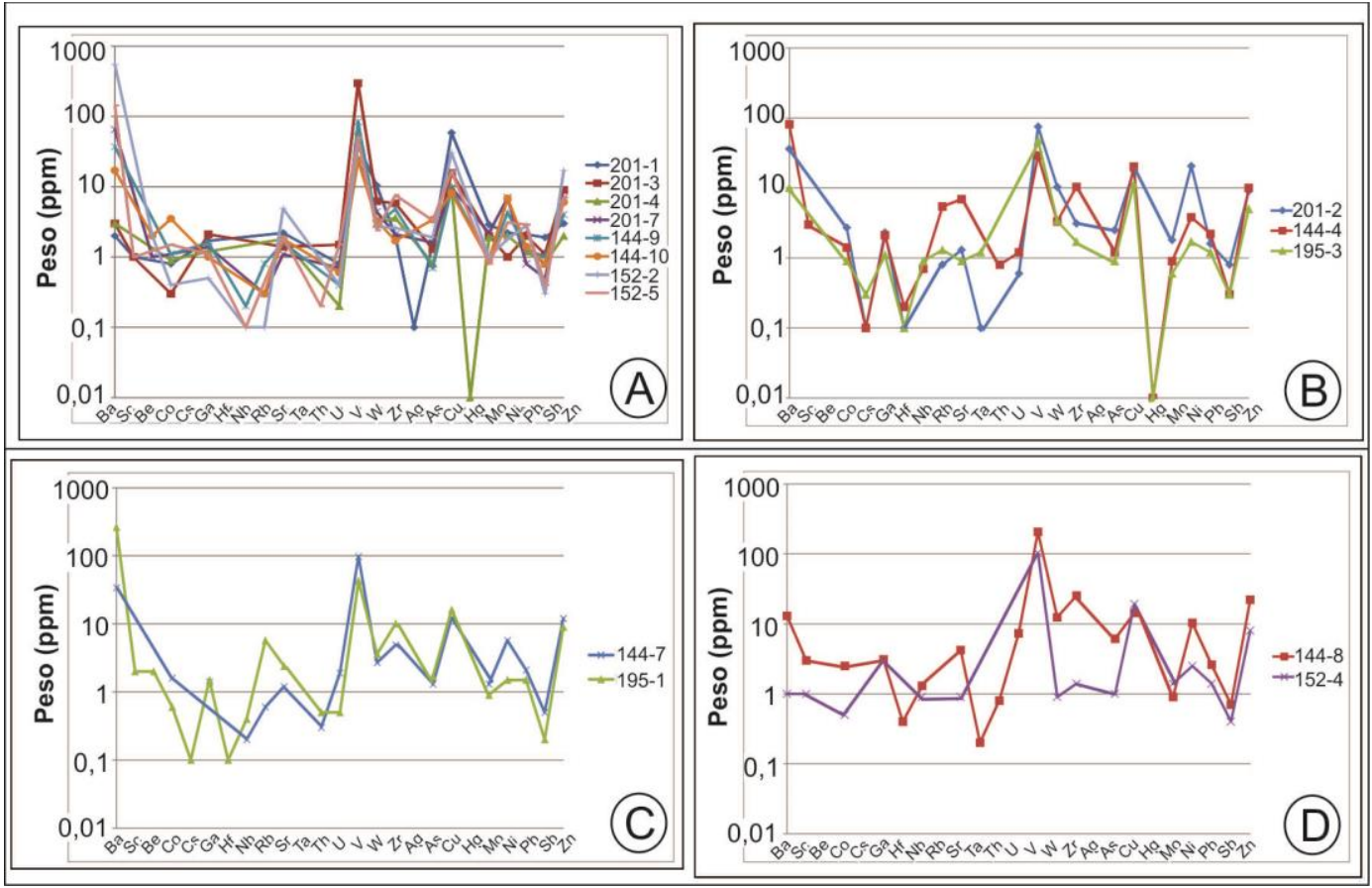

Figura 12. (A): Diagrama de elementos traço das amostras de itabirito; (B): Diagrama de elementos traço das amostras de itabirito semifriável; (C): Diagrama de elementos traço das amostras de itabirito; (D): Diagrama de elementos traço de amostras de especularita em veios de quartzo. 
Observa-se que as concentrações de Hf e Cs são menores que o limite de detecção em todas as amostras, Th $\leq 0,2 \mathrm{ppm} ; \mathrm{Zr} \leq 7,6 \mathrm{ppm} ; \mathrm{Rb} \leq 0,8 \mathrm{ppm}$ e Sc $\leq 1 \mathrm{ppm}$, sendo as maiores concentrações detectadas em amostras de ISF (FD144-4), IF (FD144-7 e FD1951), e especularita em veios de quartzo (FD144-8 e FD152-4) (Tab. 3).

\subsection{Elementos terras raras}

O conteúdo total de ETR ( $\Sigma$ ETR) varia de 4,90ppm a 63,26ppm nas amostras de IT e ISF, e de 9,00ppm a $13,30 \mathrm{ppm}$ nas amostras de IF. As amostras 144-8 e 152-2 correspondentes a especularita em veios de quartzo, apresentam os valores $97,12 \mathrm{ppm}$ e 1,08ppm, respectivamente (Tab. 3).

Os dados dos ETR foram normalizados em relação ao PAAS - Post-Archean Australian Shale - de McLennan (1989) (Fig. 13, 14-A, B e C), já que as FFBs datam do Paleoproterozóico (Rolim \& Rosière, 2011). Também foram normalizados ao condrito (Taylor e McLennan, 1985) para efeito de comparação com outros trabalhos (e.c. Bau \& Dulski, 1996; Bau \& Möller, 1993) (Fig. 15).

Quando normalizado ao condrito (Taylor \& McLennan, 1985), vide Fig. 15, o padrão dos ETR exibe proeminente anomalia negativa de Sm, provavelmente devido às diferenças de concentrações entre o Sm e o $\mathrm{Nd}$, e anomalia positiva de $\mathrm{Y}$. As amostras apresentam leve enriquecimento de elementos terras raras leves (ETRL) em relação aos elementos terras raras pesados (ETRP), com uma exceção, apresentando concentrações menores dos elementos, correspondente a cristais de especularita em veio de quartzo (amostra FD152-2). A anomalia de Eu é levemente negativa para o itabirito $\left(\mathrm{Eu} / \mathrm{Eu}^{*}{ }_{(\mathrm{CN})}=\right.$ $\left(\mathrm{Eu}_{(\mathrm{CN})} / \mathrm{Sm}_{(\mathrm{CN})}+\mathrm{Gd}_{(\mathrm{CN})}\right)=0,39-0,69$; média de 0,54), assim como anomalia de $\mathrm{Ce}$ $\left(\mathrm{Ce} / \mathrm{Ce}^{*}{ }_{(\mathrm{CN})}\right)=\left(\mathrm{Ce}_{(\mathrm{CN})} / \mathrm{La}_{(\mathrm{CN})}+\mathrm{Pr}_{(\mathrm{CN})}\right)=0,34-0,51$; média de 0,42).

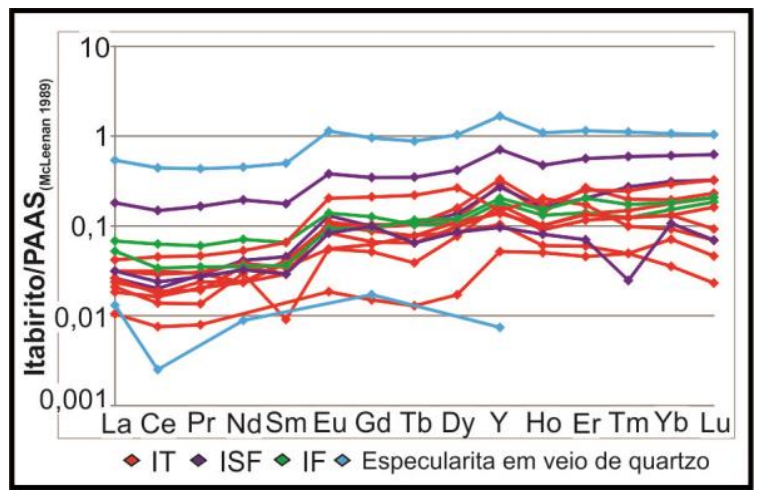

Figura 13. ETR normalizado ao PAAS (McLeenan 1989).

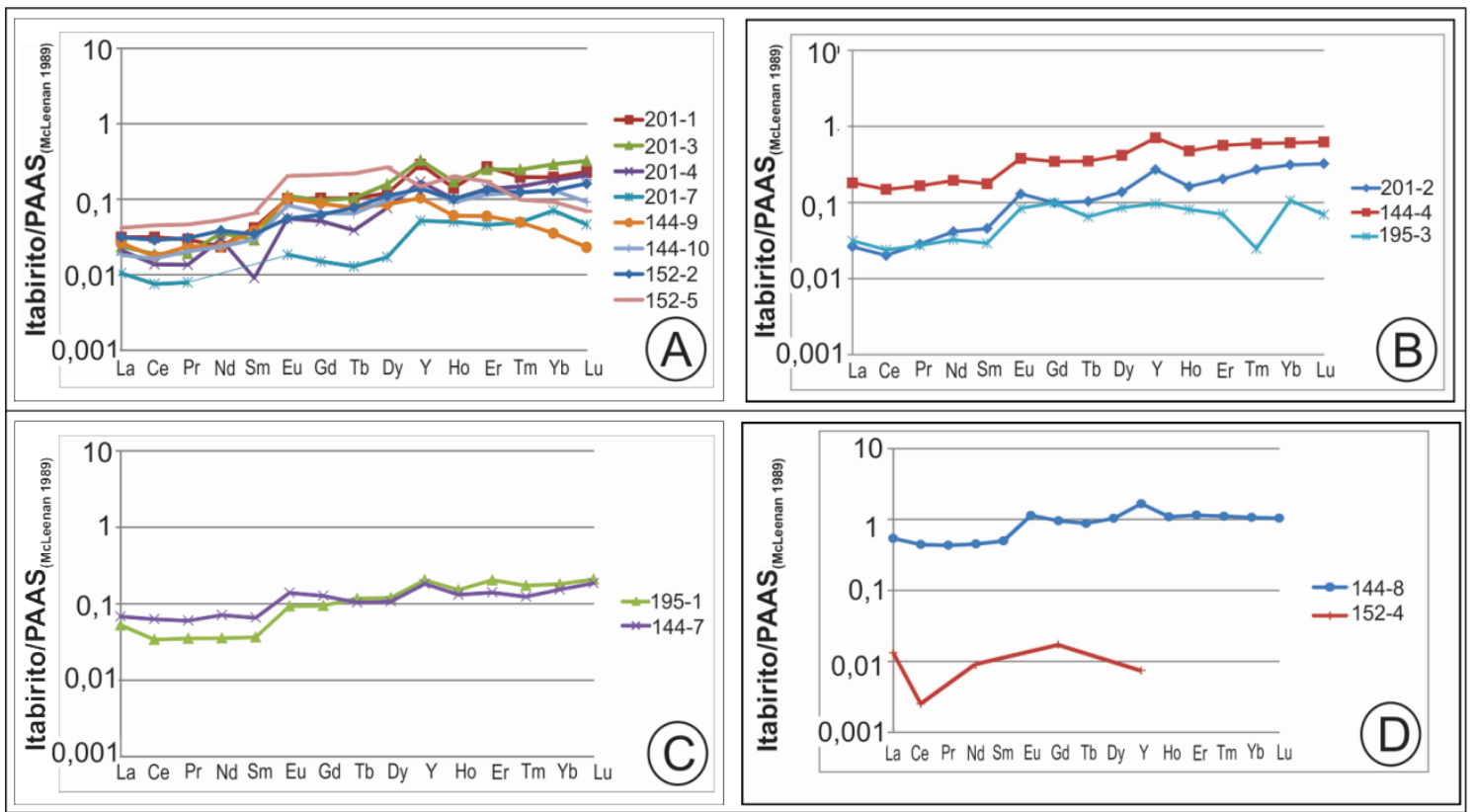

Figura 14. (A): Diagrama de ETR das amostras de itabirito normalizado ao PAAS; (B): Diagrama de ETR das amostras de itabirito friável normalizado ao PAAS; (C): Diagrama de ETR das amostras de itabirito normalizado ao PAAS; (D): Diagrama ETR das amostras de especularita em veio de quartzo normalizado ao PAAS (McLeenan, 1989). 


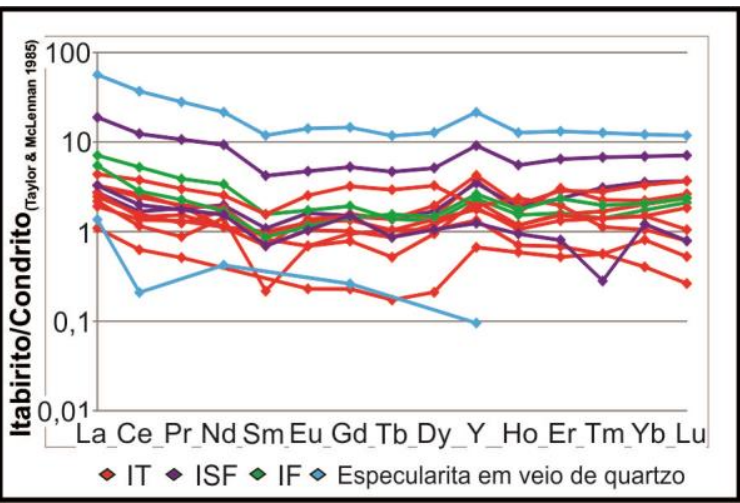

Figura 15. Diagrama dos ETR normalizados ao condrito (Taylor e McLeenan, 1985).

Conforme a Fig. 14-A, quando normalizado ao PAAS (McLeenan, 1989), o padrão do diagrama spider das amostras de IT apresenta enriquecimento em ETRP em relação aos ETRL $\left((\operatorname{Pr} / \mathrm{Yb})_{(\mathrm{SN})}=0,07-\right.$ 0,67; média de 0,25 - Planavsky et al. (2010)). A anomalia de Eu é sempre positiva $\left(\mathrm{Eu} / \mathrm{Eu}^{*}{ }_{(\mathrm{SN})}=\mathrm{Eu}_{(\mathrm{SN})} /\left(0,66 \mathrm{Sm}_{(\mathrm{SN})}+0,33 \mathrm{~Tb}_{(\mathrm{SN})}\right)=1,15-\right.$ 2,96 - Planavsky et al. (2010)) com média de 1,95. A anomalia de Ce é em geral levemente negativa, $(\mathrm{Ce} / \mathrm{Ce} *(\mathrm{SN})=(\mathrm{Ce}(\mathrm{SN}) / 0,5 \mathrm{La}(\mathrm{SN})+0,5 \operatorname{Pr}(\mathrm{SN}))=0,70-$ 1,03; média de 0,88$)$, positiva somente nas amostras 201-1 e 152-2 (Tab. 2). E a anomalia de Y é predominantemente positiva $\left(\mathrm{Y} / \mathrm{Y}^{*}(\mathrm{SN})=\right.$ $(\mathrm{Y}(\mathrm{SN}) /(0,5 \mathrm{Dy}(\mathrm{SN})+0,5 \mathrm{Ho}(\mathrm{SN}))=0,64-2,21$; média de 1,57), negativa apenas na amostra FD 152-5 $\left(Y / Y^{*}(S N)=0,64\right)$, vide Tab. 3.

\section{DISCUSSÕES}

O itabirito friável corresponde ao produto final mais avançado de intemperismo do IT, constituído de material fragmentado, poroso (Fig. 7-A). Apesar do avançado grau de intemperismo, hidróxidos de ferro não são observados no IF. Mineralogicamente os itabiritos são constituídos por quartzo, hematita e micas, sendo a maior quantidade de mica branca contida no IF (Figs. 3-C e 7-B).

O chamado ISF microscopicamente pode apresentar poros principalmente em bandas hematíticas, e maior presença de cristais de martita que o IT, contendo ainda relictos de cor róseamarrom característicos de kenomagnetita. A presença de goethita/limonita também o difere do IT.

Neste tópico, apenas o IT será discutido em termos de elementos traço e terras raras, pois, este representa a FFB fresca, abaixo do nível de intemperismo (Fig. 4), preservando informações relacionadas às condições iniciais de deposição da bacia. Os tipos ISF e IF, por apresentarem variados graus de intemperismo e não possuírem as características acima, serão tratados nas discussões apenas para fins de comparação, juntamente às amostras de hematita em veios de quartzo.

\section{Elementos Maiores}

As concentrações dos elementos maiores no IT são muito próximas aos valores estipulados por Klein (2005) e são em geral semelhantes em todos os tipos de itabirito, apesar de algumas amostras serem mais enriquecidas ou mais empobrecidas em $\mathrm{Fe}_{\text {total }}$ (Fig. 16).

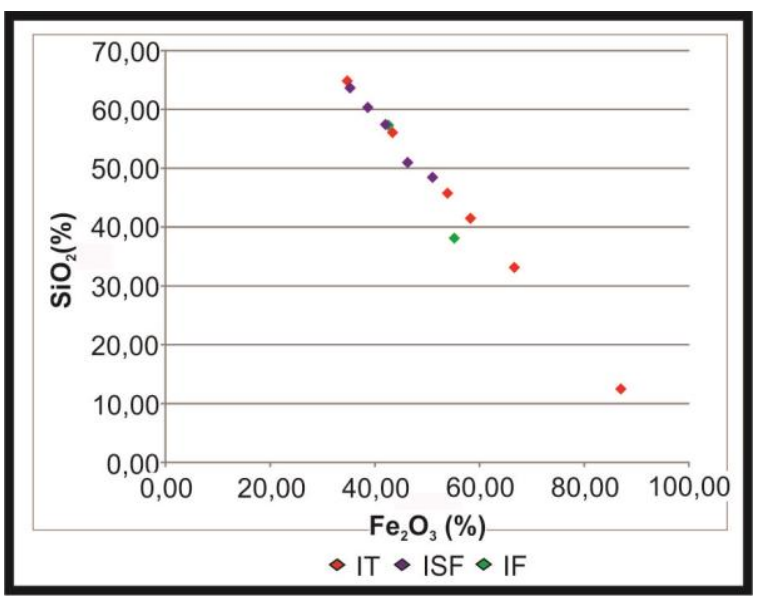

Figura 16. $\mathrm{Razão} \mathrm{SiO}_{2} \times \mathrm{Fe}_{2} \mathrm{O}_{3}$ para as amostras de itabirito.

As concentrações de $\mathrm{Al}_{2} \mathrm{O}_{3}$, baixas em todos os itabiritos, e as de $\mathrm{K}_{2} \mathrm{O}$ e $\mathrm{MgO}$, presentes em amostras de ISF e IF (Figs. 14-A, B e C e Tab. 3), provavelmente refletem a maior presença de mica e alguma clorita na rocha. Já na amostra FD144-8, correspondente a especularita em veio de quartzo, apresenta teor alto de $\mathrm{Al}_{2} \mathrm{O}_{3}(0,89 w t \%)$ e cristais de gibsita foram observados em lâmina. Concentrações de $\mathrm{P}_{2} \mathrm{O}_{5}$ e $\mathrm{CaO}$ observadas em várias amostras, correspondentes a todos os tipos de itabirito, podem estar relacionadas a cristais de apatita e carbonato, detectados apenas em análises de MEVMLA (Pires e Souza et al, em preparação).

\section{Elementos Traço}

Concentrações de elementos traço em FFBs nos fornecem informações importantes a respeito da fonte do ferro e da contribuição relativa de fluidos hidrotermais e da água do mar (Bekker et al., 2010). O comportamento de diferentes elementos traço é influenciado por muitos fatores durante a diagênese refletindo processos abióticos (condições paleoredox, contaminação clástica, grau de confinamento da bacia) e bióticos (origem da matéria orgânica, produção primária). Além disso, o comportamento dos elementos traço são muito variáveis, dependendo das condições de $\mathrm{pH}$ e Eh do ambiente durante a diagênese (Tribovillard et al., 2006).

As baixas concentrações de elementos como Th, $\mathrm{Hf}, \mathrm{Zr}, \mathrm{Rb}, \mathrm{Sc}$ e Cs (Tab. 2) sugerem que essas amostras não tiveram contribuição detrítica 
significante (Bau \& Dulski, 1996). Concentrações e razões de elementos traço como $\mathrm{U}, \mathrm{V}, \mathrm{Mo}, \mathrm{Ni}$ e $\mathrm{Cu}$, quando não relacionados à contaminação clástica, podem fornecer informações importantes a respeito das condições paleoredox durante a sedimentação (Tribovillard et al., 2006). Desta forma, Jones e Manning (1994) identificaram quatro fatores que se comportam de maneira consistente e representam índices confiáveis de condições deposicionais: U/Th, urânio autigênico [(U autigênico) = (U total) - (Th/3); Wignall \& Myers, 1988 in Jones \& Manning 1994], $\mathrm{V} / \mathrm{Cr}$ e $\mathrm{Ni} / \mathrm{Co}$, e propuseram uma tentativa de correlacioná-los.

Como parte dos elementos traço pode ser de proveniência detrítica, tais elementos foram plotados junto ao conteúdo de alumínio (elemento geralmente de origem detrítica e de mobilidade mínima durante a diagênese) nos diagramas da Fig. 17 (Tribovillard et al., 2006). Tais diagramas mostram que os elementos $\mathrm{U}, \mathrm{V}, \mathrm{Mo}, \mathrm{Ni}, \mathrm{Cu}$ e Co não estão relacionados à contaminação clástica, e dessa forma podem ser usados na interpretação do estado de oxidação da bacia.

Os índices $\mathrm{U}$ autigênico, $\mathrm{V} / \mathrm{Cr}$ e $\mathrm{Ni} / \mathrm{Co}$ apontam para um ambiente de sedimentação oxidante (o índice Th/U não foi utilizado, pois muitas amostras apresentam valores de Th abaixo do limite de detecção). Deve-se destacar no entanto que, segundo Tribovillard et al. (2006), o U pode ser remobilizado nos sedimentos se a penetração do oxigênio ocorrer na região onde o $U$ autigênico foi acumulado.

Fluxos hidrotermais também representam importante fonte potencial de elementos traço (Tribovillard et al., 2006), incluindo $\mathrm{Ba}, \mathrm{Sr}, \mathrm{Pb}$ e $\mathrm{Zn}$, e são geralmente hospedados em suítes de minerais como barita, celestita, galena, esfalerita e rodocrosita (Pujol et al., 2006).

Atividade hidrotermal exerce papel importante por liberar grandes quantidades de $\mathrm{Mn}$ e Fe, que podem influenciar a acumulação sedimentar de outros elementos traço através do seu ciclo redox (Morford et al., 2005).

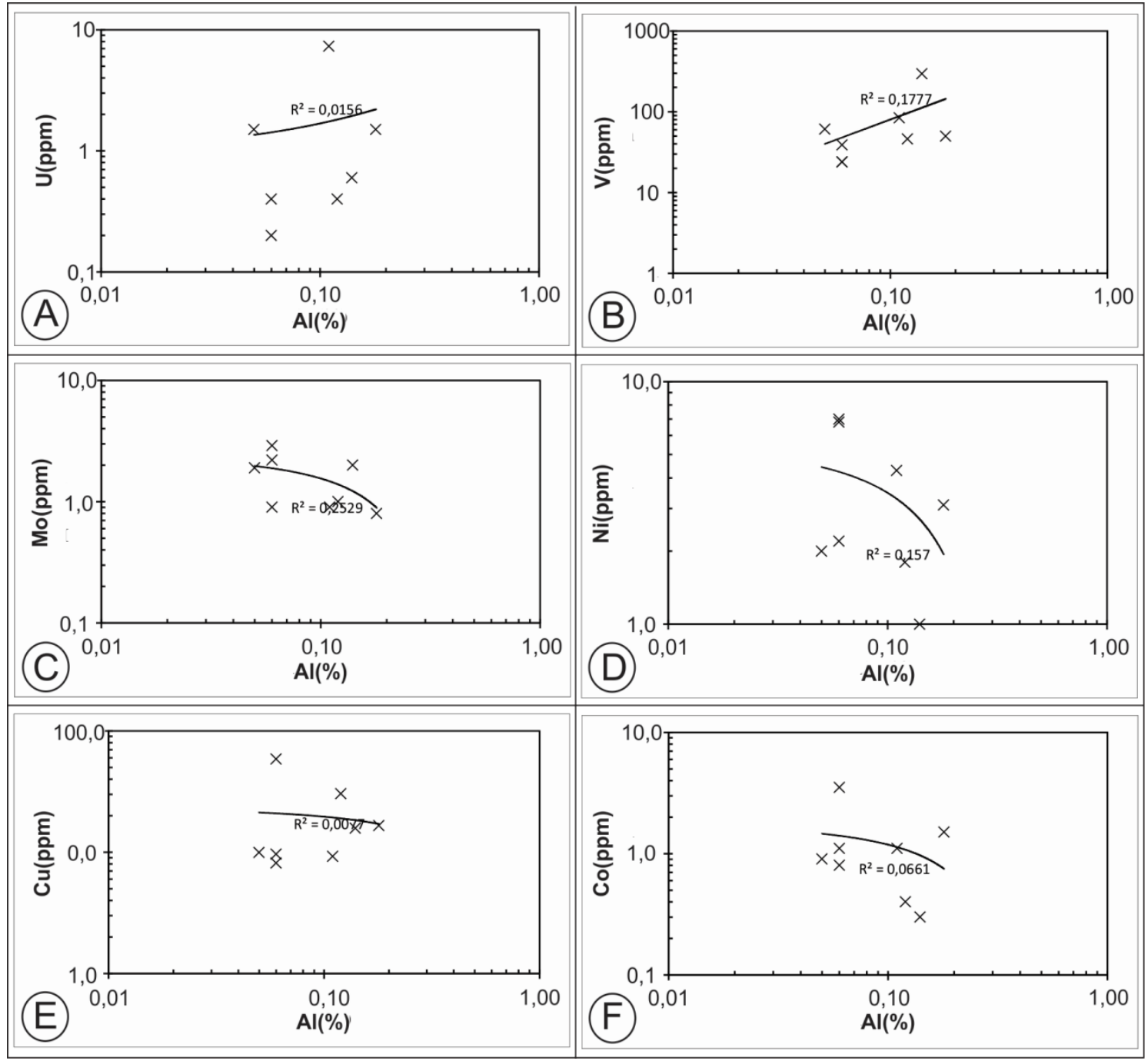

Figura 17. Diagramas de dispersão da concentração de alumínio vs. (A): U; (B): V; (C): Mo; (D): Ni; (E): Cu; (F): Co em amostra de itabirito. 
A presença de teores elevados de Ba (acima de 100ppm; Tab. 3) em duas amostras de IT (FD152-2 e FD152-5) é corroborada pelas análises em MEVMLA, onde a fase mineral barita foi detectada (Pires e Souza et al., em preparação). Fontes de Ba para o oceano são partículas biogênicas, detritos continentais, efluentes hidrotermais e remobilização/precipitação diagenética (Dymond et al., 1992 in Tribovillard et al., 2006) ou ainda associadas ao metamorfismo durante a evolução tectônica da bacia.

A presença de As foi identificada em todas as amostras de IT com teores < 2ppm, com exceção de duas amostras com concentrações maiores (Tab. 3). As outras amostras de itabirito apresentam valores de As semelhantes ao IT. A amostra FD144-8 (especularita em veio de quartzo) apresentou concentração mais alta desse elemento (6,1ppm). Segundo (Taylor \& McLennan, 1985), a crosta continental apresenta concentrações extremamente baixas de As, com média de < 2ppm. Sedimentos detríticos e oceânicos também são fortemente depletados em As, enquanto fluidos hidrotermais podem ser enriquecidos de 2 a 500 vezes em relação ás concentrações da água do mar (Pecoits, et al., 2009).

\section{Elementos Terras raras}

O padrão do diagrama spider normalizado ao PAAS (McLeenan, 1989) apresenta enriquecimento em ETRP em relação aos ETRL (Fig. 14-A) para amostras de itabirito. Segundo Planavsky et al. (2010), FFBs do Paleoproterozoico inferior e arqueanas são caracterizadas pela depleção de ETR leves, enquanto as do Paleoproterozoico superior mostram razões ETR leves e pesados acima e abaixo do padrão dos folhelhos.

Planavsky et al. (2010) explicam que depleção em ETR leves desenvolve-se em corpos de água ricos em oxigênio devido à remoção preferencial destes em relação aos ETR pesados pelos oxidróxidos de $\mathrm{Mn}$-Fe e outras superfícies dada a reatividade diferencial das partículas de ETR.

A anomalia de $Y$ é predominantemente positiva nas amostras estudadas, com o valor médio da razão $\mathrm{Y} / \mathrm{Ho}$ igual a 41,13, muito próximo ao sugerido por Planavsky et al. (2010) para FF do Paleoproterozóico inferior (39).

A anomalia de $\mathrm{Ce}_{(\mathrm{SN})}$ é em geral levemente negativa para as amostras de IT, assim como a de $\mathrm{Ce}_{(\mathrm{CN})}$. Normalmente, ambientes marinhos modernos apresentam forte anomalia negativa de $\mathrm{Ce}_{(\mathrm{SN})}$ quando normalizados ao folhelho, enquanto águas subóxicas e anóxicas carecem de anomalias significativas de $\mathrm{Ce}_{(\mathrm{SN})}$ devido à redução da dissolução de partículas fixadoras de $\mathrm{Mn}-\mathrm{Fe}$ (German et al., 1991; Byrne e Sholkovitz, 1996 in Planavsky et al., 2010). Porém, nas amostras trabalhadas, $\left(\mathrm{Pr} / \mathrm{Pr}^{*}\right)_{S N}=0,80$ e $\left(\mathrm{Ce} / \mathrm{Ce}{ }^{*}\right)_{S N}=0,88$, o que segundo Bau \& Dulski (1996) indica uma anomalia positiva de $\operatorname{La}_{S N}$ (Fig. 18) e não necessariamente de um comportamento anômalo do Ce. A ausência de anomalia negativa de $\mathrm{Ce}$ em FFBs puras, sugere que o conteúdo de oxigênio na água do mar do Arqueano/Proterozóico era alto o suficiente para oxidar o $\mathrm{Fe}$, mas muito baixo para oxidar quantidades significativas de $\mathrm{Ce}$ (Bau \& Dulski, 1996).

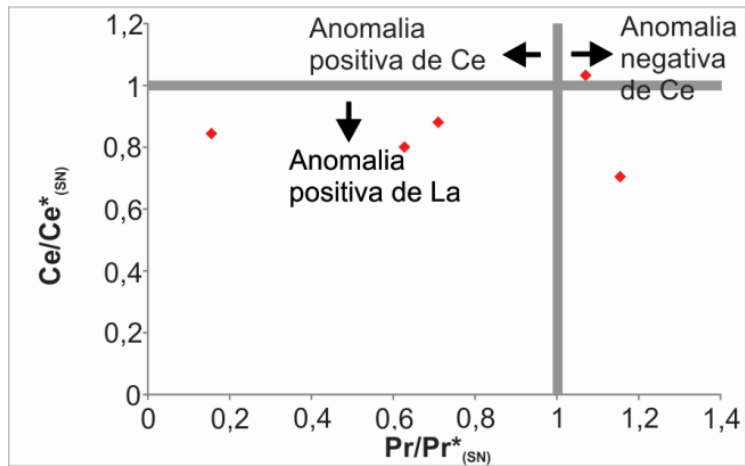

Figura 18. Diagrama de razões $\mathrm{Ce} / \mathrm{C} e^{*}{ }_{(S N)}$ vs.Pr/Pr* ${ }_{(S N)}$ para amostras de itabirito (baseado em Bau \& Dulski, 1996).

Os valores de $\mathrm{Ce} / \mathrm{Ce}^{*}{ }_{(S N)}$ vs. Y/Ho (Fig. 19) para amostras de IT, não interceptam a linha que define o campo de contaminação pelas argilas (exceto as amostras FD201-1 e FD152-5 que estão muito próximas à linha), confirmando a ausência de contaminação clástica significativa no IT.

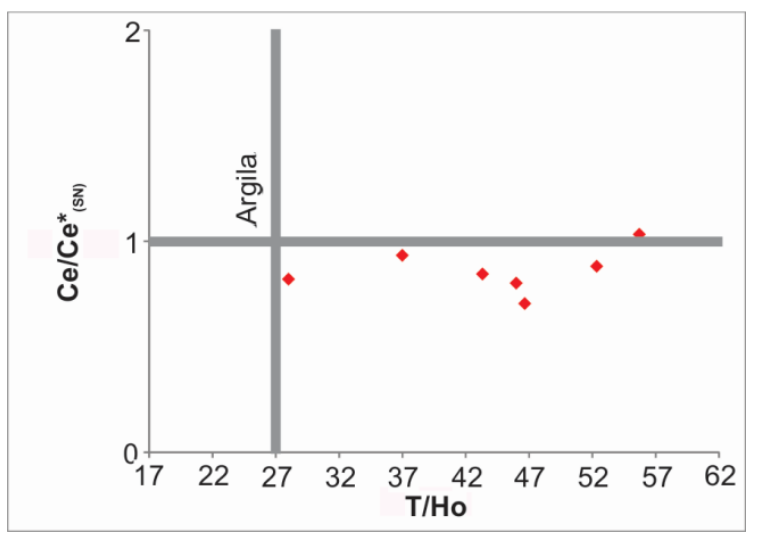

Figura 19. Diagrama binário Ce/Ce ${ }_{(S N)}^{*}$ vs. Y/Ho (Pecoits, 2010) para amostras de itabirito.

As médias das razões $(\mathrm{Eu} / \mathrm{Sm})_{\mathrm{SN}}$ e $(\mathrm{Eu} / \mathrm{Sm})_{\mathrm{CN}}$ obtidas nas amostras de IT foram 3,23 e 1,68, respectivamente. Segundo Bau \& Möller (1993), independentemente da proveniência, idade, ambiente sedimentar, e grau metamórfico, as FFBs precambrianas apresentam tipicamente $(\mathrm{Eu} / \mathrm{Sm})_{\mathrm{SN}}>$ 1. Já as razões $(\mathrm{Eu} / \mathrm{Sm})_{\mathrm{CN}}$ são $>1$ para as FFBs mais velhas que $2,3 \mathrm{Ga}$, ao passo que FFBs mais jovens apresentam $(\mathrm{Eu} / \mathrm{Sm})_{\mathrm{CN}} \sim 1$ ou valores ligeiramente menores (a amostra FD201-4 apresentou um valor muito alto, aumentando a média, sem ela esse valor cai para 1,43$)$. As razões $(\mathrm{Sm} / \mathrm{Yb})_{S N}=0,38$ e $(\mathrm{La} / \mathrm{Sm})_{\mathrm{CN}}$ = 4,20, indicam ausência de contaminação clástica (Bau \& Dulski, 1996). As Razões de Sm/Yb vs. Eu/Sm e de $\mathrm{Eu} / \mathrm{Eu}^{*}{ }_{(\mathrm{CN})}$ vs. $(\mathrm{Sm} / \mathrm{Yb})_{(\mathrm{CN})}$ (Figs. 20-A e B) evidenciam que a contaminação por fluidos hidrotermais de alta temperatura nos itabiritos foi insignificante. 

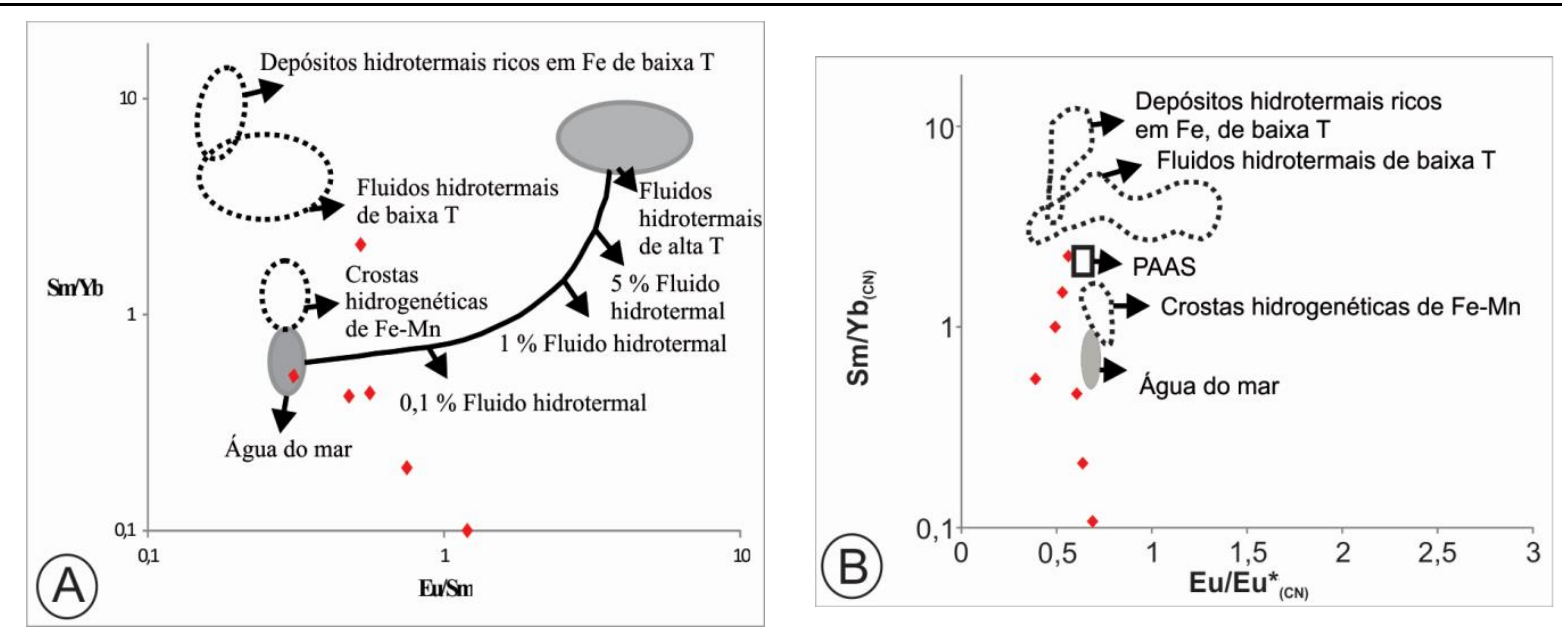

Figura 20. Diagramas binários com dados de amostras de itabirito (A): $S m / Y b$ vs. Eu/Sm; (B): Diagrama binário Sm/Yb $(C N)$ vs. Eu/Eu* (CN). Dados: fluidos hidrotermais de baixa T (Michard et al., 1983); depósitos hidrotermais ricos em Fe de baixa T (Puteanus et al., 1991); fluidos hidrotermais de alta T (Bau \& Dulski, 1996); crostas de Fe-Mn hidrogenéticas (Bau et al., 1996); água do mar do Pacífico (Alibo \& Nozaki, 1999). Ambos os diagramas modificados de Alexander et al. (2008).

\section{CONCLUSÕES}

No depósito da Serra do Sapo, as FFBs são metamorfizadas e intensamente cisalhadas com transposição e obliteração das estruturas primárias. Minérios de ferro de baixo teor são representados por IT, IF e ISF.

$O$ itabirito consiste em uma FFB não intemperizada, com as bandas ricas em ferro constituídas predominantemente por hematita e martita subordinada. A hematita é texturalmente variável exibindo cristais microlamelares, subédricos, finos e grossos e agregados anédricos porosos. Associados às bandas ricas em Fe ocorrem cristais de mica branca aciculares ou placóides e cristais de clorita. Bandas ricas em quartzo contem cristais de mica branca, clorita e carbonato (exclusivo do IT), contudo, cristais isolados de hematita estão presentes e inclusos.

Itabirito semifriável representa a FFB parcialmente intemperizada. Apresenta cristais euédricos a subédricos de martita e relictos de kenomagnetita são comuns. Por vezes apresenta goethita. O IF é o produto final de intemperismo, apesar da ausência de hidróxidos de ferro. Ocorre tanto na zona superior quanto inferior do saprolito. Além dos óxidos presentes no IT, o IF pode apresentar cristais de martita contendo relictos de cor rósea-marrom de kenomagnetita, sendo o tipo mais rico em mica.

Veios de quartzo são ricos em hematita lamelar de granulação muito grossa, deformada e fraturada, mas podem apresentar cristais microlamelares e aglomerados anédricos subordinados. Contem ainda mica branca, gibsita e carbonato.

Análises geoquímicas mostram que as FFBs, representadas pelo itabirito, estão livres de contaminação clástica, pelos baixos teores de elementos de afinidade detrítica (Th, $\mathrm{Hf}, \mathrm{Zr}, \mathrm{Rb}, \mathrm{Sc}$,
$\mathrm{Cs}$ ) e pelos diagramas $\mathrm{U}, \mathrm{V}, \mathrm{Mo}, \mathrm{Ni}, \mathrm{Cu}$ e $\mathrm{Co} v s . \mathrm{Al}_{2} \mathrm{O}_{3}$. Teores elevados de $\mathrm{Ba}, \mathrm{Zn}$ e As em algumas amostras sugerem contribuição hidrotermal.

O padrão do diagrama spider normalizado ao PAAS (McLeenan, 1989) mostra depleção de ETRL em relação aos ETRP, anomalia de $Y$ predominantemente positiva, valor médio da razão $\mathrm{Y} / \mathrm{Ho}=41,13$, anomalias de $\mathrm{Eu}_{(\mathrm{SN})}$ positivas, com média de 1,95 e $(\mathrm{Eu} / \mathrm{Sm})_{\mathrm{CN}} \sim 1$, características comuns para FFB do Paleoproterozoico inferior. A maior parte das amostras apresenta anomalia positiva de $\mathrm{La}_{S \mathrm{~N}}$, pois $\left(\mathrm{Pr} / \mathrm{Pr}{ }^{*}\right)_{S N} \sim 1$ e $\left(\mathrm{Ce} / \mathrm{Ce}{ }^{*}\right)_{S N}<1$. A razão $\mathrm{Ce} / \mathrm{Ce}^{*}{ }_{(S N)}$ vs. $\mathrm{Y} / \mathrm{Ho}$, a média da razão $(\mathrm{Eu} / \mathrm{Sm})_{S N}>1$, valores de $(\mathrm{La} / \mathrm{Sm})_{\mathrm{CN}}>1,(\mathrm{Sm} / \mathrm{Yb})_{S N}<<$ 1 , $\left(\mathrm{Eu} / \mathrm{Eu}^{*}\right)_{\mathrm{SN}}>1$, e a razão $(\mathrm{Sm} / \mathrm{Yb})_{\mathrm{CN}}=0,79$ são características de rochas livres de contaminação clástica. As razões de $\mathrm{Sm} / \mathrm{Yb}$ vs. Eu/Sm e de $\mathrm{Eu} / \mathrm{Eu}^{*}{ }_{(\mathrm{CN})} \quad$ vs. $(\mathrm{Sm} / \mathrm{Yb})_{(\mathrm{CN})}$ evidenciam que a contribuição por fluidos hidrotermais de alta temperatura nos itabiritos foi insignificante.

Desta forma, conclui-se que as FFBs da Serra do Sapo são provenientes de sedimentos puros, visto sua composição mineralógica majoritariamente composta por quartzo e hematita e sua composição química com teores baixos de elementos indicativos de contaminação clástica e hidrotermal.

\section{AGRADECIMENTOS}

Agradecem à empresa Anglo American pela oportunidade e pelo apoio logístico e financeiro através do projeto "Caracterização mineralógica, mineroquímica, morfologia dos componentes dos diferentes tipos de minério da Serra do Sapo e Itapanhoacanga". Ao Programa de Pós-graduação em Geologia do IGC-UFMG e à Fapemig pela bolsa da primeira autora. Os autores agradecem ainda aos revisores e editores da GEONOMOS. 


\section{REFERÊNCIAS}

Alexander B.W., Bau M., Anderson P., Dulski P. 2008. Continentally-derived solutes in shallow Archean seawater: Rare earth element and $\mathrm{Nd}$ isotope evidence in iron formation from the $2.9 \mathrm{Ga}$ Pongola Supergroup, South Africa. Geochimica et Cosmochimica Acta, 72: 378-394.

Almeida Abreu P.A. 1993. A evolução geodinâmica da Serra do Espinhaço Meridional, Minas Gerais, Brasil. Tese de Doutoramento, Geowiss. Fakultät Universidade de Freiburg, $150 \mathrm{p}$.

Almeida-Abreu P.A., Knauer L.G., Hartmann M.B., Vieira dos Santos G.G., Guimarães M.L.V., Abreu F.R., Schrank A., Pflug R. 1989. Estratigrafia, faciologia e tectônica do Supergrupo Espinhaço na região de Serro - Conceição do Mato Dentro, Minas Gerais, Brasil. Zbl. Geol. Paläont., 5/6: 857-873.

Almeida-Abreu P.A. \& Renger F.E. 2002. Serra do Espinhaço Meridional: um orógeno de colisão do Mesoproterozóico. Revista Brasileira de Geociências, 32(1): 1-14.

Alibo D.S. \& Nozaki Y. 1999. Rare earth elements in seawater: particle association, shale normalization, and Ce oxidation Geochimica et Cosmochimica Acta, 63: 363-372.

Bau M. \& Dulski P. 1996. Distribution of yttrium and rare-earth elements in the Penge and Kuruman Iron-Formations, Transvaal Supergroup, South Africa. Precambrian Research, 79:37-55.

Bau M. \& Möller P. 1993. Rare earth element systematics of the chemically precipitated component in Early Precambrian ironformations and the evolution of the terrestrial atmospherehydrosphere-lithosphere system. Geochimica et Cosmochimica Acta, 57: 2239-2249.

Bekker A., Slack J. F., Planavsky N., Krapež B., Hofmann A., Konhauser K. O., Rouxel O. J. 2010. Iron Formation: The Sedimentary Product of a Complex Interplay among Mantle, Tectonic, Oceanic, and Biospheric Processes. Society of Economic Geologists, Inc. Economic Geology, 105: 467-508.

Byrne R. \& Sholkovitz E. 1996. Marine chemistry and geochemistry of the lanthanides. In: K.A.Jr. Gschneider \& L. Eyring (eds.). Handbook on the physics and chemistry of the rare earths. Amsterdam, Elsevier, 23, p.: 497-593.

Brito Neves, B.B. \& Cordani, U.G. 1991. Tectonic evolution of South America during the Late Proterozoic. Precambrian RÈs. 53: 23-40.

Chemale Jr.F., Dussin I.A., Alkmim F.F., Martins M.S., Queiroga G., Armstrong R., Santos M.N.,2012. Unraveling a Proterozoic basin history through detrital zircon geochronology: The case of the Espinhaço Supergroup, Minas Gerais, Brazil. Gondwana Research. 22(1):200-206.

Dymond J., Suess E., Lyle, M., 1992. Barium in deep-sea sediments: a geochemical proxy for paleoproductivity. Paleoceanography 7, 163-181.

Dossin I.A., Uhlein A., Dossin T.M. 1984. Geologia da Faixa Movel Espinhaço em sua porção meridional, MG . In: Cong. Bras. Geol., 33, Anais 7: 3118-3134.

Dossin T.M., 1985. Geologia e geoquímica das formações ferríferas da Serra da Serpentina,Conceição do Mato Dentro, Minas Gerais. Dissertação de Mestrado, Universidade de Brasília, 140p.

Fogaça A.C.C.; Almeida Abreu P.A., Schorscher H. D. 1984. Estratigrafia da sequência supracrustal arqueana da porção mediana central da Serra do Espinhaço Meridional, Minas Gerais. In: Cong. Br. Geol., 33, Anais 6: 2654-2667.
German C. R., Holliday B. P. and Elderfield H. (1991) Redox cycling of rare earth elements in the suboxic zone of the Black Sea. Geochim. Cosmochim. Acta 55, 3553-3558.

Grossi-Sad J. H., Mourão M. A. A., Guimarães M. L. V., Knauer L. G. 1997. Geologia da Folha Conceição do Mato Dentro. In: Grossi-Sad J.H., Lobato L.M., Pedrosa-Soares A.C., SoaresFilho B.S. (coordenadores e editores). Projeto Espinhaço em Cd-Rom (textos, mapas e anexos). Belo Horizonte, COMIG, p. 2533-2693.

Hagemann S.G., Rosiere C., Gutzmer J., Beukes N.J. 2008. Glossary of Terms Banded Iron-Formation related high-grade iron ore. In: Hagemann S.G., Rosiere C., Gutzmer J., Beukes N. (eds.) High-grade BIF-related iron mineralization. Reviews In Economic Geology, 15: 411-414.

Jones B. \& Manning D.A.C. 1994. Comparison of geochemical indices used for the interpretation of paleoredox conditions in ancient mudstones. Chem. Geol. 114: 111-129.

Klein C. 2005. Some Precambrian banded iron-formations (BIFs) from around the world: Their age, geologic setting, mineralogy, metamorphism, geochemistry, and origin. American Mineralogist, 90: 1473-1499.

Knauer L. G. 1990. Evolução geológica do Pré-cambriano da porção centro-oeste da Serra do Espinhaço Meridional e metalogênese associada. Dissertação de Mestrado, Universidade de Campinas, 298 p.

Knauer L. G. 2007. O Supergrupo Espinhaço em Minas Gerais: considerações sobre sua estratigrafia e seu arranjo estrutural. Geonomos, 15(1): 81-90.

Knauer L. G.\& Grossi-Sad J. H. (1997). Geologia da Folha Serro. In: Grossi-Sad J.H., Lobato L.M., Pedrosa-Soares A.C., SoaresFilho B.S. (coordenadores e editores). 1997. Projeto Espinhaço em CdRom (textos, mapas e anexos). Belo Horizonte, COMIG, p. 2057-2316

Kullerud, G., Donnay, G., and Donnay, J.D.H., 1969, Omission solid solution in magnetite: kenotetrahedral magnetite: Zeitschrifft der Kristallographie, 128: 1-17.

Machado N., Schrank A., Abreu F.R. de, Knauer L.G., AlmeidaAbreu P.A., 1989. Resultados preliminares da geocronologia $\mathrm{U} / \mathrm{Pb}$ na Serra do Espinhaço Meridional. In: $5^{\circ}$ SIMP. GEOL., Núcleo de MG - $1^{\circ}$ SIMP. GEOL. Núcleo Brasília, SBG - Núcleo MG, Anais. Belo Horizonte, BOL. 10:171-174

Martins-Neto M.A. 1998. O Supergrupo Espinhaço em Minas Gerais: Registro de uma bacia rifte-sag do Paleo/Mesoproterozóico. Revista Brasileira de Geociências, 28(2): 151-168.

McLennan S.M. 1989. Rare earth elements in sedimentary rocks: influence of provenance and sedimentary processes. In: Rollinson H. R. (eds). Using Geochemical Data: Evaluation, Presentation, Interpretation. Longman Group, UK, p.:352.

Michard A., Albarède F., Michard G., Minster J.F., Charlou J.L. 1983. Rare-earth elements and uranium in high-temperature solutions from East Pacific Rise hydrothermal vent field $\left(13^{\circ} \mathrm{N}\right)$. Nature, 303: 795-797.

Morford J.L., Emerson S.R., Breckel E.J., Kim S.H., 2005. Diagenesis of oxyanions ( $V, U, R e$, and $M o$ ) in pore waters and sediments from a continental margin. Geochimica et Cosmochimica Acta 69: 5021-5032.

Pecoits E., Gingras M.K., Barley M.E., Kappler A., Posth N.R., Konhauser K.O. 2009. Petrography and geochemistry of the Dales Gorge banded Fe formation: Paragenetic sequence, source and implications for palaeo-ocean chemistry. Precambrian Reasearch, 172: 163-187.

Pedrosa-Soares A.C., Dardenne M.A., Hasui Y., Castro F.D.C., Carvalho M.V.A. 1994. Nota Explicativa dos Mapas Geológico, 
Metalogenético e de Ocorrências Minerais do Estado de Minas Gerais, Escala 1:1.000.000. SEME/COMIG, Belo Horizonte, $231 \mathrm{pp}$.

Pflug, R. 1968. Observações sobre a estratigrafia da Série Minas na região de Diamantina, Minas Gerais. Rio de Janeiro, DNPM/DGM, 20 p. (Notas Prel. 142).

Planavsky N. Bekker A., Rouxel O.J., Kamber B., Hofmann A., Knudsen A., Lyons T. W. 2010. Rare earth element and yttrium compositions of Archean and Paleoproterozoic Fe formations revisited: New perspectives on the significance and mechanisms of deposition. Geochimica et Cosmochimica Acta, 74(22): 6387-6405.

Pujol F., Berner Z., Stüben D. 2006. Palaeoenvironmental changes at the Frasnian/Famennian boundary in key European sections: Chemostratigraphic constraints. Palaeogeography, Palaeoclimatology, Palaeoecology, 240(1): 120-145.

Puteanus D., Glasby G.P., Stoffers P., Kunzendorff H., 1991. Hydrothermal iron-rich deposits from the Teahitia-Mehitia and Macdonald hot spot areas. Southwest Pacific Marine Geology, 98: 389-409.

Renger FE, Noce CM, Romano AW, Machado N (1994) Evolução sedimentar do Supergrupo Minas: $500 \mathrm{Ma}$. de registro geológico no Quadrilátero Ferrífero, Minas Gerais, Brasil. Geonomos 2(1): 1-11.

Rolim V. K. 2014. As formações ferríferas da região de Conceição do Mato Dentro - MG: posicionamento estratigráfico, evolução tectônica, características geoquímicas e gênese dos minérios. Exame de qualificação (Doutorado), Instituto de Geociências, Universidade Federal de Minas Gerais.

Rolim V. K. \& Rosière C. A. 2011. The Conceição do Mato Dentro Iron Formation Province in southeastern Brazil. In: 11th
Biennial SGA Meeting, Antofagasta, Chile, Extended Abstract, 927-929.

Schobbenhaus, C. 1993. Das Mittlere Pwtewzoikum Brasiliens mitbesonderer Ber,cksichtung dís zentralen Osten: Eine Revision. Tese de Doutorado, Universidade de Freiburg, 166 p.

Schobbenhaus, C. 1996. As tafrogêneses superpostas Espinhaço e Santo Onofre, Estado da Bahia: Revisão e novas propostas. Revista Brasileira de Geociências, 26(4): 265-276.

Scholl W.U. \& Fogaça A.C.C. 1979. Estratigrafia da Serra do Espinhaço na região de Diamantina. Simp. Geol. MG, 1, Diamantina Anais, p. 55-73.

Taylor S.R. \& McLennan, S.M. 1985. The continental crust: its composition and evolution. Blackwell Scientific, Oxford. In: Rollinson H. R. 1993. Using Geocgemical Data: Evaluation, Presentation, Interpretation. Longman Scientific \& Technical, London, $352 \mathrm{pp}$.

Tribovillard N., Algeo T. J., Lyons T.W., Riboulleau A. 2006. Trace metals as paleoredox and paleoproductivity proxies: an update. Chemical Geology, 232: 12-32.

Trompette, R.; Uhlein, A.; Silva, M.E. Karmann, I. 1992. The Brasiliano São Francisco Cráton revised (central Brazil). /. South Am. Earth Sei., 6: 49-57.

Uhlein A. 1991. Transição cráton-faixa dobrada: exemplo do Cráton do São Francisco e da Faixa Araçuaí (Ciclo Brasiliano) no estado de Minas Gerais. Aspectos estratigráficos e estruturais. Tese de Doutorado, Universidade de São Paulo, $295 p$

Wignall P.B. \& Myers K.J., 1988. Interpreting the benthic oxygen levels in mudrocks: a new approach. Geology, 16: 452-455. 